University of South Florida

DIGITAL COMMONS

Digital Commons @ University of

@ UNIVERSITY OF SOUTH FLORIDA

South Florida

8-26-2005

\title{
Modeling Tephra Sedimentation from a Ruapehu Weak Plume Eruption
}

Costanza Bonadonna

University of South Florida, costanza@usf.edu

J. C. Phillips

University of Bristol

B. F. Houghton

University of Hawaii at Manoa

Follow this and additional works at: https://digitalcommons.usf.edu/gly_facpub

Part of the Geochemistry Commons, Geology Commons, and the Geophysics and Seismology Commons

\section{Scholar Commons Citation}

Bonadonna, Costanza; Phillips, J. C.; and Houghton, B. F., "Modeling Tephra Sedimentation from a Ruapehu Weak Plume Eruption" (2005). Geology Faculty Publications. 4.

https://digitalcommons.usf.edu/gly_facpub/4

This Article is brought to you for free and open access by the Geology at Digital Commons @ University of South Florida. It has been accepted for inclusion in Geology Faculty Publications by an authorized administrator of Digital Commons@ University of South Florida. For more information, please contact digitalcommons@usf.edu. 


\title{
Modeling tephra sedimentation from a Ruapehu weak plume eruption
}

\author{
C. Bonadonna \\ Department of Geology, University of South Florida, Tampa, Florida, USA
}

Centre for Environmental and Geophysical Flows, University of Bristol, Bristol, UK

Department of Geology and Geophysics, University of Hawai'i at Manoa, Honolulu, Hawaii, USA

J. C. Phillips

Centre for Environmental and Geophysical Flows, University of Bristol, Bristol, UK

B. F. Houghton

Department of Geology and Geophysics, University of Hawai'i at Manoa, Honolulu, Hawaii, USA

Received 1 November 2004; revised 31 March 2005; accepted 3 May 2005; published 26 August 2005.

[1] We present a two-dimensional model for sedimentation of well-mixed weak plumes, accounting for lateral spreading of the cloud, downwind advection, increase of volumetric flux in the rising stage, and particle transport during fallout. The 17 June 1996 subplinian eruption of Ruapehu produced a bent-over plume that rose to a height of $8.5 \mathrm{~km}$ in a wind field with an average velocity of $24 \mathrm{~m} \mathrm{~s}^{-1}$ and generated a narrow deposit on land extending up to $200 \mathrm{~km}$ from vent. The sedimentation from the Ruapehu plume was dominated by coarse ash, with all the blocks and most of the lapilli falling while the plume was still rising. Particles with diameter $<125 \mu \mathrm{m}$ show three accumulation maxima, one coincident with a secondary maximum in the total tephra deposit about $150 \mathrm{~km}$ from the vent. Numerical modeling shows that the plume started spreading horizontally beyond about $30 \mathrm{~km}$ from vent. Investigations also show that Fickian diffusion can be a good approximation to the crosswind spreading of both "vigorous" and "low-energy" weak plumes, but a wide range of diffusion coefficients is to be expected, with the largest values necessary to describe the most vigorous weak plumes such as Ruapehu. One-dimensional and two-dimensional simulations show that tephra sedimentation must have been subvertical. This feature, also supported by direct observations, can be the result of the turbulence structure of the local wind field and convective instabilities, which could also have played an important role in the generation of the pronounced sinuosity shown by the Ruapehu deposit.

Citation: Bonadonna, C., J. C. Phillips, and B. F. Houghton (2005), Modeling tephra sedimentation from a Ruapehu weak plume eruption, J. Geophys. Res., 110, B08209, doi:10.1029/2004JB003515.

\section{Introduction}

[2] Volcanic plumes can be defined as strong or weak depending on whether the plume vertical velocity is much greater or much smaller than the wind speed respectively, and a practical discriminating condition is suggested by Sparks et al. [1997] for a plume height of $10 \mathrm{~km}$ and a wind velocity of $20 \mathrm{~m} \mathrm{~s}^{-1}$, on the basis of typical vertical velocities for plumes. Strong plumes typically rise above the tropopause developing a subvertical column that spreads laterally into a turbulent current once its density reaches the atmospheric density (i.e., neutral buoyancy level), whereas weak plumes typically develop in the troposphere following bent-over trajectories as a result of the strong wind advection

Copyright 2005 by the American Geophysical Union. 0148-0227/05/2004JB003515\$09.00
(Figure 1). In this paper we refer to the base of horizontal volcanic clouds and bent-over plumes as "current base."

[3] Strong plumes do not significantly interact with the wind in the subvertical column (i.e., convective region), whereas the entire weak-plume trajectory is determined by the plume buoyancy flux and addition of momentum from wind field by entrainment [Coelho and Hunt, 1989]. Beyond the initial gas thrust region, weak plumes show a bent-over trajectory and rise first due to buoyancy, then due to momentum, and eventually spread subhorizontally around the neutral buoyancy level (Figure 1b). As a result of interaction with atmospheric wind, the dynamics of weak plumes is much more complex than that of strong plumes, and their trajectory is typically fitted empirically [Briggs, 1969; Turner, 1973].

[4] Weak plumes can also bifurcate in distal areas for reasons that are still not entirely understood: the distribution of pressure around the vortices, constant plume buoyancy, 


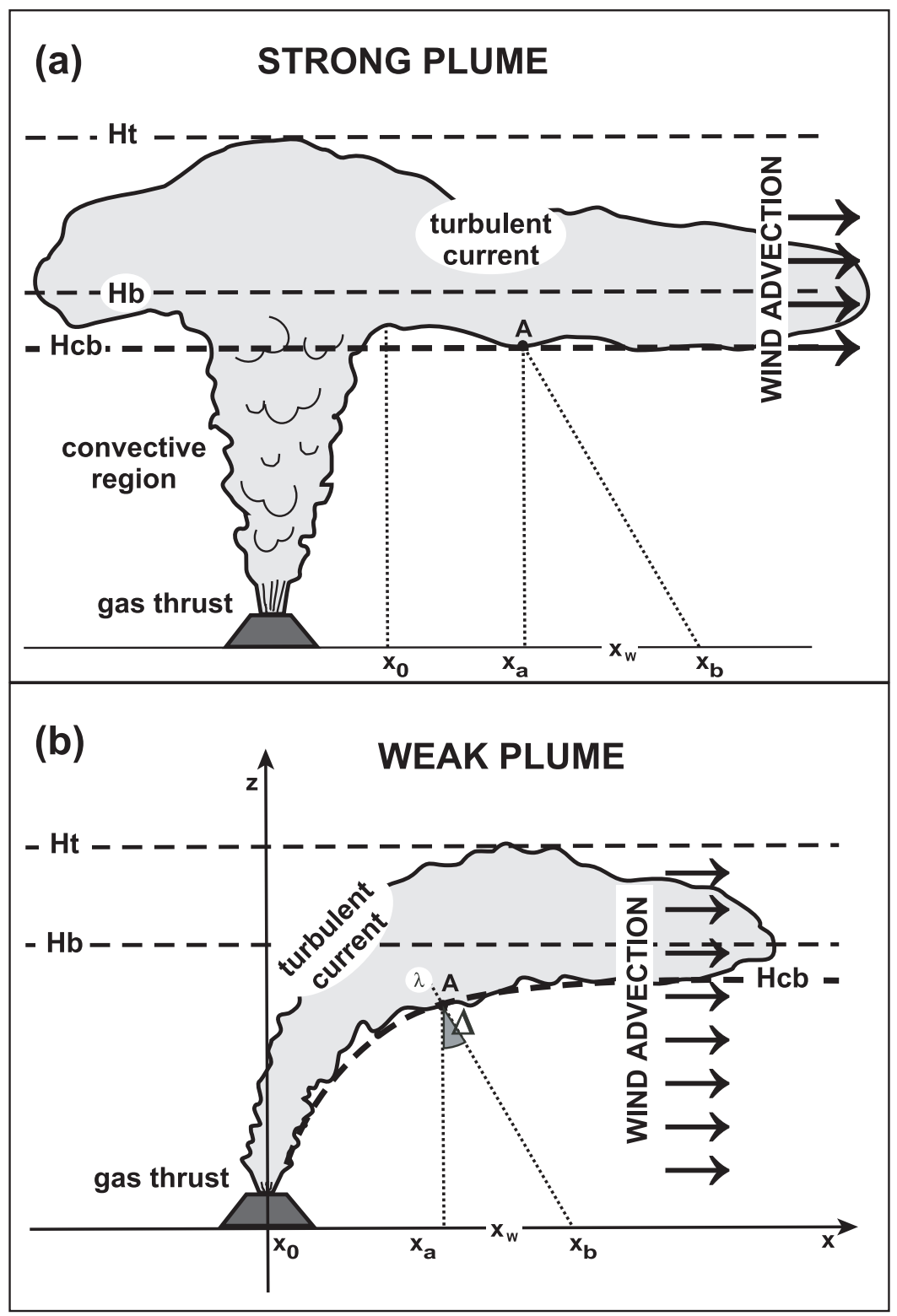

Figure 1. Sketch of the main features of (a) a strong and (b) a weak plume developing in a wind field. Strong plumes are characterized by a subvertical convective region that spreads laterally around the level of neutral buoyancy $\left(H_{b}\right)$. Weak plumes are characterized by vertical velocities lower than the wind velocities. As a result, they develop into bent-over plumes that start spreading subhorizontally around the neutral buoyancy level. In the case of vertical tephra sedimentation a particle falling from the current base at a point $\mathrm{A}$ will reach the ground at a distance $x_{a}$ from the vent. In the case of a plume developing in a wind field a particle falling from the current base at a point $\mathrm{A}$ is likely to reach the ground at a point $x_{b}$ depending on the wind velocity and the particle terminal velocity between the current base and the ground. $x_{w}$ is the distance between $x_{a}$ and $x_{b}$ proportional to the ratio between wind velocity and particle terminal velocity. $\Delta$ is the angle of the particle fall trajectory $\lambda$. For constant wind velocity and particle terminal velocity, a given particle size will fall at constant $\Delta$. Here $x_{o}$ is the source of the turbulent current. The coordinate system $(x, y, z)$ is also shown with $x$ in the downwind direction and $y$ in the crosswind direction.

release of latent heat by evaporating water droplets within the plume and the impact of the vortex structure with a density interface have all been suggested [Ernst et al., 1994]. Bifurcation of weak volcanic plumes has been observed directly and in satellite images, and some examples of bilobate tephra deposits have been reported. Bifurcation is stronger for strongly bent-over plumes [Ernst et al., 1994], but does not appear to affect plume rise significantly [Cunningham et al., 2005].

[5] The understanding of sedimentation from strong volcanic plumes has significantly progressed in the last two decades and models have been developed which show good agreement with field data [e.g., Armienti et al., 1988; Bonadonna et al., 1998; Bursik et al., 1992a, 1992b; Carey 


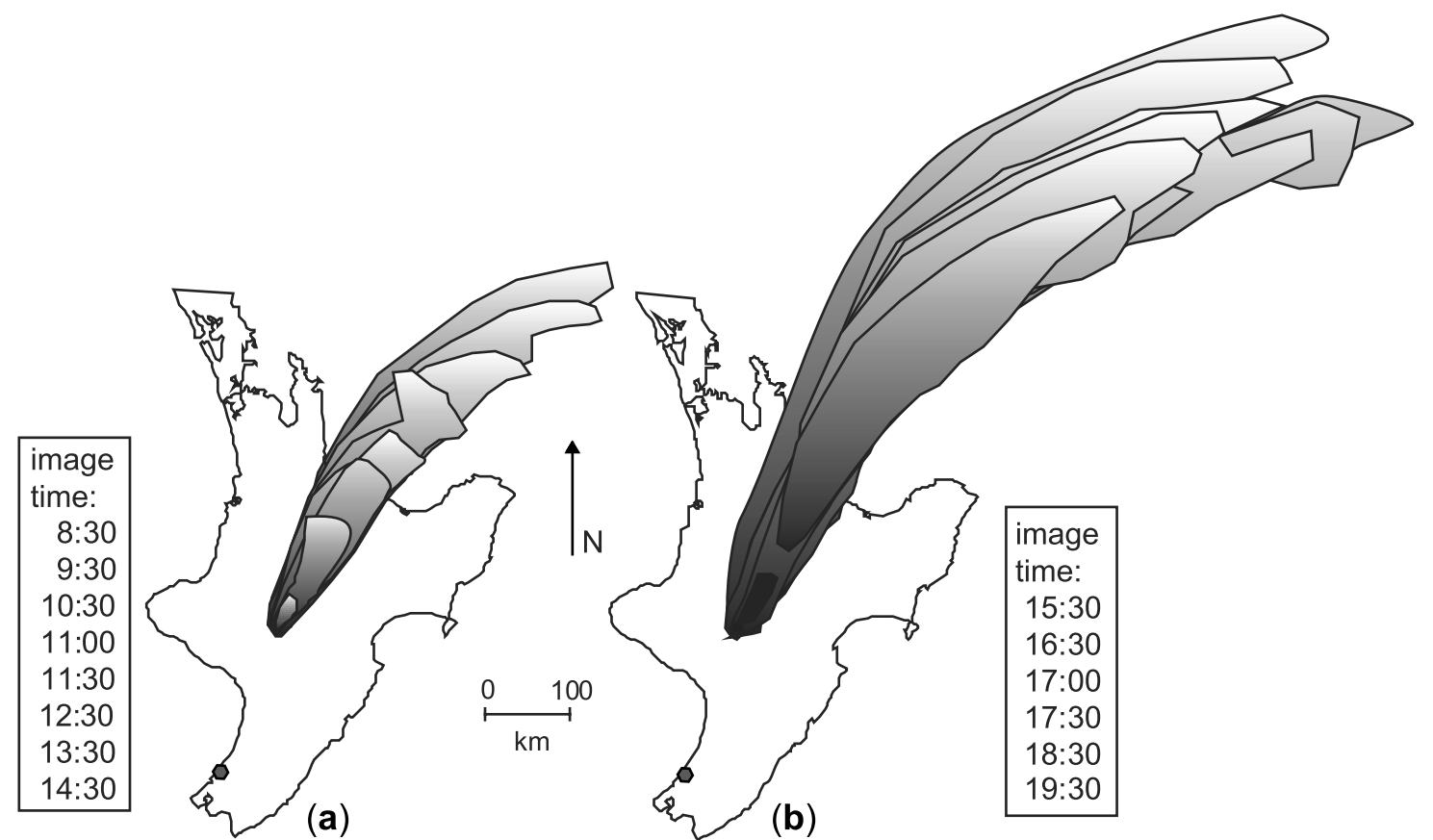

Figure 2. Plume dimensions as sketched from images of (a) the first and (b) the first plus the second Ruapehu plumes mapped from satellite imagery (Geostationary Meteorological Satellite provided by JMA; from Houghton et al. (submitted manuscript, 2005)). Images were taken at 30-min intervals and are overlapped in order to show the downwind and crosswind spreading relative to the original position. Times of the images shown are also indicated (New Zealand Time). Note that at 1530, two plumes are visible, and by 1630 the two plumes have merged (first and second image of Figure 2b). The circle indicates the position of the Paraparaumu Aerodrome where the radiosonde data were recorded. See color version of this figure in the HTML.

and Sparks, 1986; Koyaguchi and Ohno, 2001; Macedonio et al., 1988; Sparks et al., 1992; Suzuki, 1983]. The dynamics of weak plumes has mainly been studied theoretically and experimentally [Ernst et al., 1994; Fric and Roshko, 1994] and the sedimentation from these plumes has not been investigated in detail.

[6] In this paper, the models by Bursik et al. [1992a] and Bonadonna and Phillips [2003] are coupled with empirical descriptions by Briggs [1969] and theoretical analysis by Turner [1973] to account for sedimentation from bent-over plumes. Our sedimentation model for weak plumes is based and calibrated on the bent-over plume produced during the 17 June 1996 subplinian eruption of Ruapehu, New Zealand (B. F. Houghton et al., The 17 June 1996 eruption of Ruapehu volcano, New Zealand: The anatomy of a windadvected subplinian fall deposit, submitted to Bulletin of Volcanology, 2005, hereinafter referred to as Houghton et al., submitted manuscript, 2005). In this paper, we refer to this plume and the corresponding tephra deposit as "Ruapehu". The Ruapehu deposit represents the best studied tephra deposit from weak plumes available, for which also crucial plume observations were made at the time of the eruption and plume images were captured at 30 -min intervals over the duration of the eruption by a Geostationary Meteorological Satellite (GMS-5) provided by the Japan Meteorological Agency (JMA).

[7] The Ruapehu eruption provided direct observations of a volcanic plume interacting with the atmospheric wind field. It started at 0650 and produced two sustained pulsating plumes between 0830 and 1300 and between
1500 and 1700 respectively. All times in this paper are indicated as local New Zealand time (NZT). These plumes were bent over by a SSW wind with speed between $13 \mathrm{~m} \mathrm{~s}^{-1}$ at $3 \mathrm{~km}$ and $34 \mathrm{~m} \mathrm{~s}^{-1}$ at $9 \mathrm{~km}$ (heights are above sea level (asl), and wind speeds are from radiosonde data obtained at 1200 and 0000 NZT from the Paraparaumu Aerodrome, which is located on the south of the North Island of New Zealand, $40.54^{\circ} \mathrm{S}, 174.59^{\circ} \mathrm{E}$, Figure 2 [Prata and Grant, 2001]). The maximum plume height was reached by the distal portion of the first plume already detached from vent (i.e., $8.5 \mathrm{~km}$ asl [Prata and Grant, 2001]) and the two plumes merged by 1630 . Bifurcation occurred around $800 \mathrm{~km}$ from vent when the eruption lost its vigor (i.e., after 1700 hours). Tephra deposits from the two plumes overlapped due to a uniform wind direction to NNE during the eruption and therefore were treated as if generated by a single weak plume (Houghton et al., submitted manuscript, 2005).

[8] In this paper we first present a summary of the observations of the Ruapehu plume and its deposit. We then describe the rise, spreading and mass transport in a weak volcanic plume using empirical descriptions of plume motion and a diffusive model.

\section{Plume Spreading and Depositional Characteristics of the Ruapehu Eruption}

\subsection{Plume Spreading}

[9] The Ruapehu eruption occurred during a very clear day and the resulting plume was captured on a sequence of 

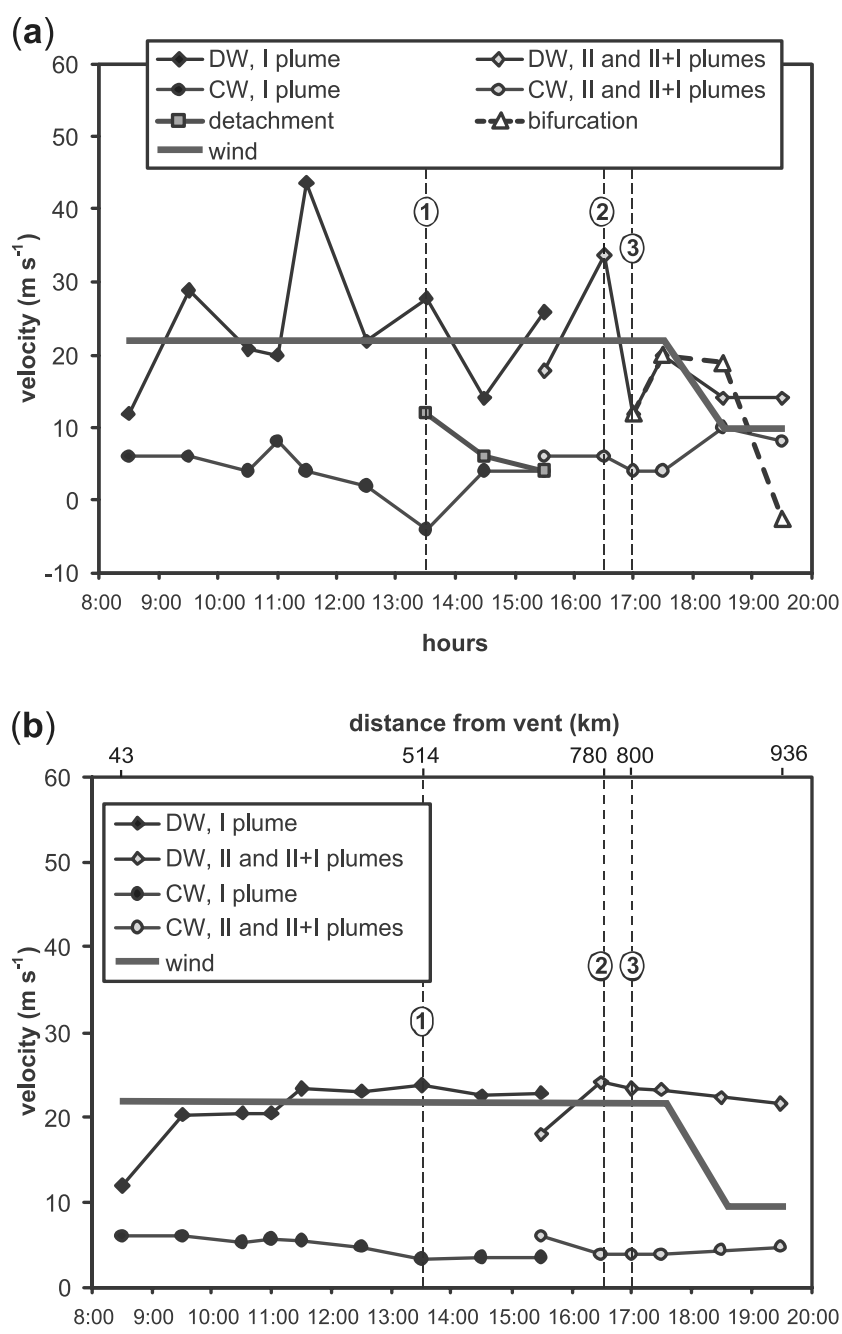

hours

Figure 3. (a) Differential and (b) total velocities of the Ruapehu plume spreading as calculated from the satellite images in Figure 2. Differential velocities are calculated between consecutive pairs of images, whereas total velocities are calculated with respect to the initial plume position. Downwind spreading (DW) is indicated with diamonds, whereas crosswind spreading $(\mathrm{CW})$ is indicated with circles. The solid line indicates the wind velocity at the height of plume spreading (radiosonde data from Paraparaumu Aerodrome with general wind-velocity accuracies of $\pm 5 \mathrm{~m} \mathrm{~s}^{-1}$ ). The position of the Paraparaumu Aerodrome is indicated in Figure 2. Circled 1, 2, and 3 indicate three crucial times: 1 is when the first plume detaches from vent, 2 is when the first and the second plume merge, and 3 is when the final plume starts bifurcating. "Detachment" is the velocity of plume detachment from vent (squares), whereas "bifurcation" is the spreading velocity of the two newly formed plume lobes as seen in satellite images (triangles). Crucial distances from vent are also indicated on a horizontal secondary axis in Figure $3 b$. See color version of this figure in the HTML. satellite images taken every 30 min between 0830 and 1930 by GMS-5 (Figure 2) (Houghton et al., submitted manuscript, 2005). The downwind (i.e., along the dispersal axis) and crosswind (i.e., lateral) plume velocities were calculated from these images (Figure 3). Plume velocities were calculated both between consecutive pairs of images (i.e., differential velocities) and with respect to the initial plume position (i.e., total velocities). The plume did not spread significantly upwind, with a maximum upwind spreading of $7 \mathrm{~km}$ reached between 1100 and 1130 with a velocity of $4 \mathrm{~m} \mathrm{~s}^{-1}$ (Figure 2). The differential velocity plot shows a pulsating downwind spreading both for the first and the second plume (Figure 3a), with the second plume being characterized by lower velocities (averages of 24 and $19 \mathrm{~m} \mathrm{~s}^{-1}$ respectively). The differential downwind velocity varied between 11 and $44 \mathrm{~m} \mathrm{~s}^{-1}$ with the maximum value reached by the first plume between 1100 and 1130 at about 260-340 km from the vent (Figure 3a). The second plume was shorter lived and the corresponding downwind velocity started decreasing around 1700 hours when bifurcation also started taking place. The bifurcation point moved at the same downwind rate of the expanding plume during the first 1.5 hours and then it rapidly stopped spreading (Figure 3a). Satellite observations were only available for 2.5 hours after bifurcation started at about $800 \mathrm{~km}$ downwind of the vent (Figure 2).

[10] The pulsating character of the plume with velocities much higher and slightly lower than the mean wind velocity at the height of neutral buoyancy (Figure 3a) results in a total plume velocity only slightly higher than the mean wind velocity for most of the duration of the eruption (Figure 3b). The mean downwind velocity for the first and the second plume is 21 and $22 \mathrm{~m} \mathrm{~s}^{-1}$ respectively, with a mean wind velocity at the neutral buoyancy level of $20 \mathrm{~m} \mathrm{~s}^{-1}$ (radiosonde data; Figure $3 \mathrm{~b}$ ). The plume spread at significantly higher velocity than the wind only when the two plumes merged (after 1630). It is important to notice that the differences between plume-spreading rate and wind velocity are of the same scale of general accuracies for radiosonde data (i.e., $\pm 5 \mathrm{~m} \mathrm{~s}^{-1}$ (A. J. Prata, personal communication 2004)) and that the radiosonde data were actually taken about $300 \mathrm{~km}$ south of Ruapehu (Paraparaumu Aerodrome; Figure 2).

[11] The differential crosswind velocity shows very little variation between 4 and $10 \mathrm{~m} \mathrm{~s}^{-1}$, with the largest velocities reached between 1100 and $1130\left(8 \mathrm{~m} \mathrm{~s}^{-1}\right)$, corresponding to the maximum downwind and upwind velocity, and after $1830\left(8-10 \mathrm{~m} \mathrm{~s}^{-1}\right)$, probably due to the plume bifurcation (Figure 3a). A negative crosswind velocity is shown at 1330 due to the detachment of the first plume from vent. After the first plume detaches from vent (1300), the total crosswind velocity decreases down to $4 \mathrm{~m} \mathrm{~s}^{-1}$ and starts increasing again when the two plumes merge (1630) (Figure 3b). However, the plume keeps on spreading both downwind and crosswind even after it has detached from vent. The differential detachment velocity of the plume is lower than the downwind spreading velocity, showing that the plume must have kept on spreading downwind even after it detached from vent (Figure 3a). Detachment velocity is here defined as the 


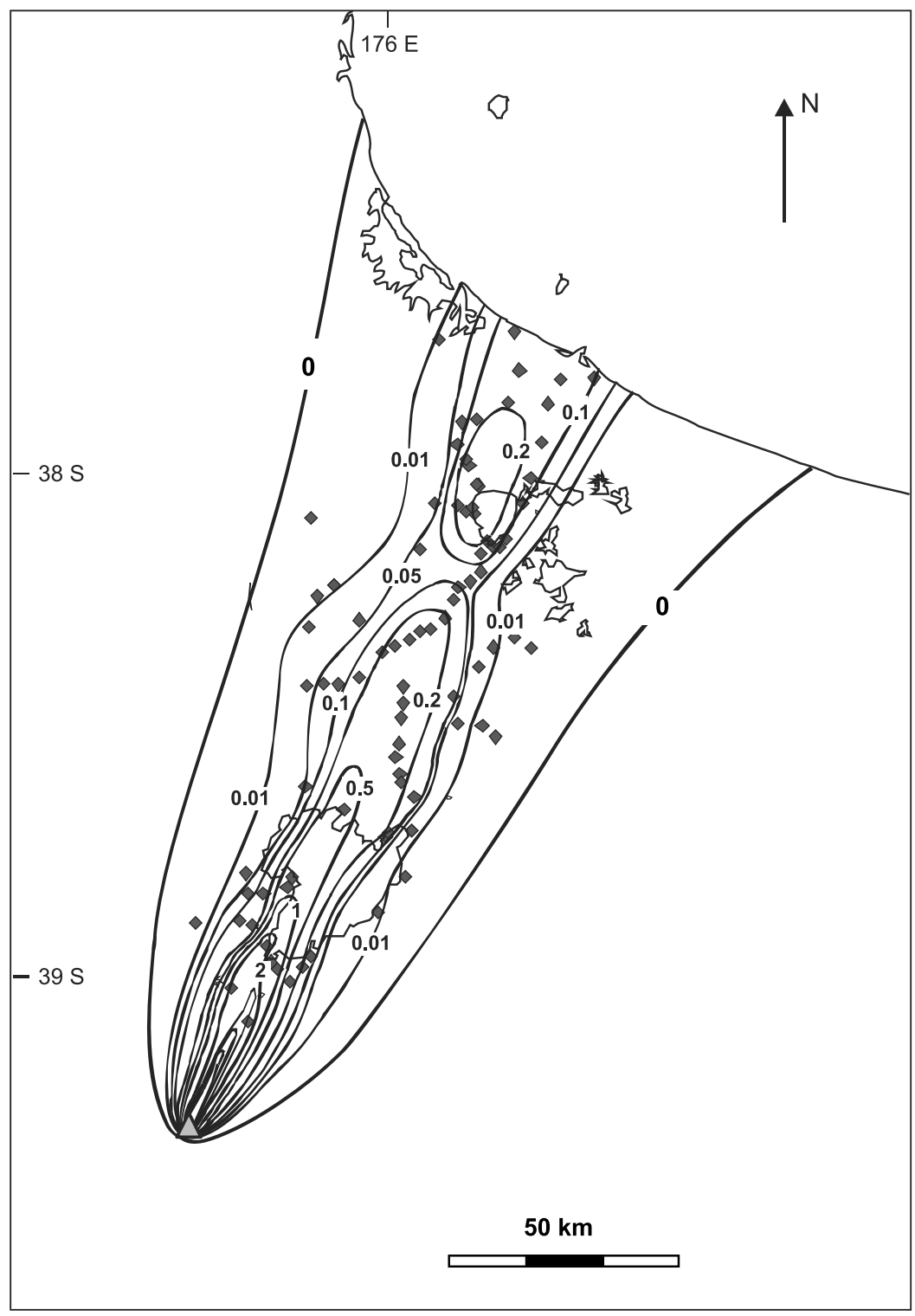

Figure 4. Isomass contours of the tephra deposit produced during the Ruapehu eruption $\left(\mathrm{kg} \mathrm{m}^{-2}\right)$ (Houghton et al., submitted manuscript, 2005). The line of "zero" deposit is also shown in order to compare plume spreading and deposit lateral expansion. The triangle indicates the position of the eruptive vent, and the diamonds indicate the sample points in medial and distal area (see Figures 6-8 for proximal sample points). See color version of this figure in the HTML.

horizontal velocity of the detached plume at the end of the sustained phase.

\subsection{Deposit}

[12] Even though the Ruapehu eruption was characterized by two distinct sustained phases with a 2-hour gap, the resulting tephra was uniformly deposited along a dispersal axis NNE (Figure 4). Medial samples from the two phases have very similar grain size and the distal deposit cannot be subdivided into two units. Thus the resulting deposit is treated as a single unit, which forms a narrow lobe extending more than $200 \mathrm{~km}$ from the volcano, with a pronounced secondary mass/thickness maximum at about $150 \mathrm{~km}$ downwind and no significant deposition upwind (Figure 4). The deposit is characterized by a rapid mass/thickness decrease with distance in proximal areas, varying from about $3000 \mathrm{~kg} \mathrm{~m}^{-2}$ a few hundreds meters from the vent (equivalent to a thickness of about $2.4 \mathrm{~m}$ ) to about $500 \mathrm{~kg} \mathrm{~m}^{-2}$ (equivalent to a thickness of about $0.4 \mathrm{~m}$ ) about $2 \mathrm{~km}$ downwind from the vent and less than $0.5 \mathrm{~km}$ crosswind. Distal thinning is less extreme, declining from values of $200 \mathrm{~g} \mathrm{~m}^{-2}$ to $100 \mathrm{~g} \mathrm{~m}^{-2}$ in about $4 \mathrm{~km}$ both downwind and crosswind at about $150 \mathrm{~km}$ from the vent (Figure 4).

[13] Samples along the dispersal axis show a unimodal grain size distribution with mode decreasing regularly from $4 \mathrm{~mm}(-2 \Phi)$, around $0.4 \mathrm{~km}$ downwind from the vent, to $63 \mu \mathrm{m}(4 \Phi)$ beyond $150 \mathrm{~km}$ (Figures 5a and 5b). Blockand lapilli-sized fragments (i.e., with diameter $>64 \mathrm{~mm}$ and 2-64 $\mathrm{mm}$ respectively) are confined within 0.4 and $40 \mathrm{~km}$ downwind from the vent respectively, with most of the lapilli being deposited within the first $30 \mathrm{~km}$ (wt $\%>0.1$; 

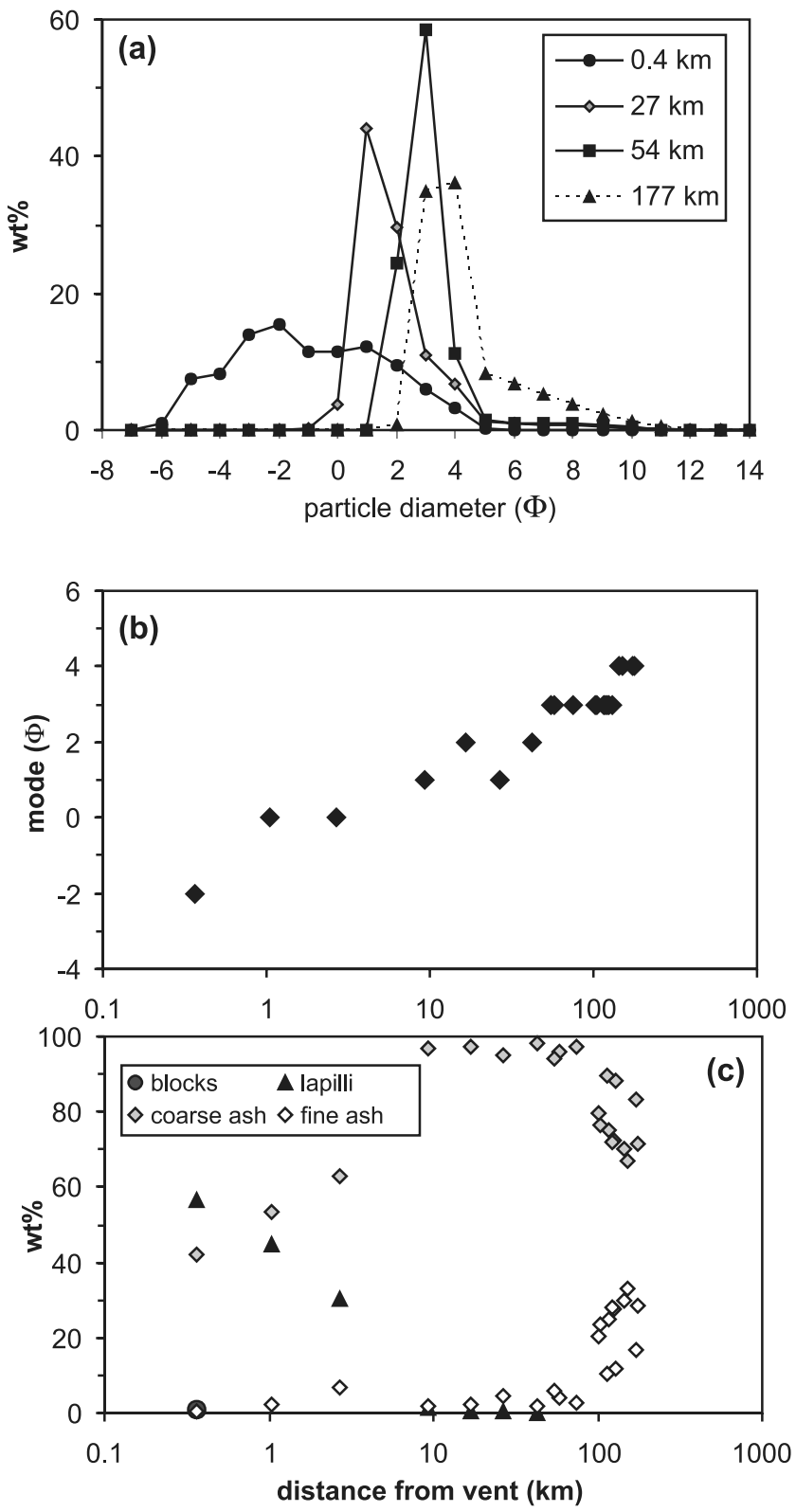

Figure 5. Granulometric data from the Ruapehu deposit showing (a) grain size distribution of individual samples collected along the dispersal axis (NNE) at different distances from the vent (from Houghton et al., submitted manuscript, 2005), (b) semilog plot of variation with distance from vent of the grain size distribution mode of samples collected along the dispersal axis (all unimodal), and (c) semilog plot of variation with distance from vent of the wt $\%$ of lapilli, coarse-ash and fine-ash fraction (i.e., particles with diameter $64-2 \mathrm{~mm}, 2-0.063 \mathrm{~mm}$, and $<0.063 \mathrm{~mm}$, respectively) for samples collected along the dispersal axis. $\Phi=-\log _{2} \mathrm{~d}$, where $\mathrm{d}$ is the particle diameter in millimeters. See color version of this figure in the HTML.

Figure 5c). Sedimentation between 10 and $75 \mathrm{~km}$ from vent is mostly dominated by coarse ash (i.e., particles with diameter $2 \mathrm{~mm}$ to $63 \mu \mathrm{m}$ ) and the fine ash fraction (i.e., $<63 \mu \mathrm{m}$ ) remains consistently below $10 \mathrm{wt} \%$ up to about $75 \mathrm{~km}$ downwind from the vent (Figure 5c). Fine ash reaches values between $20-35 \mathrm{wt} \%$ between 100 and $200 \mathrm{~km}$ downwind for most samples analyzed, but the largest size fraction in the distal area is coarse ash (Figure $5 \mathrm{c}$ ).

[14] Particles with diameter $>1 \mathrm{~mm}, 1 \mathrm{~mm}$ to $125 \mu \mathrm{m}$, and $<125 \mu \mathrm{m}$ show different dispersal characteristics, which are summarized in the isomass maps of Figures 6, 7, and 8. Particles with diameter $>1 \mathrm{~mm}$ fall off steeply within the first $50 \mathrm{~km}$, whereas particles with diameter $<125 \mu \mathrm{m}$ show three maxima (Figures 6 and 8), one coincident with the secondary mass/area maximum at about $150 \mathrm{~km}$ from the vent shown by the whole deposit (Figure 4). Particles with diameter between $125 \mu \mathrm{m}$ and $1 \mathrm{~mm}$ show a more gradual thinning of mass/area over the whole land deposit with the exception of a very rapid decrease within the first $2 \mathrm{~km}$ (Figure 7).

\section{Modeling Weak Volcanic Plumes \\ 3.1. Plume Rise}

[15] Beyond their source region, weak plumes have been described as a single flow advected by wind, with three different bending-over stages identified by fitting of empirical curves [Briggs, 1969]. In this paper we only describe and model the spreading and sedimentation of a weak volcanic plume beyond the gas thrust region. Here, the weak plume rises as a turbulent-diffused current first due to buoyancy, then due to momentum and, finally, it starts spreading horizontally when it reaches the neutral buoyancy level [Sparks et al., 1997]. Its flow structure is retained along the whole trajectory, due to the strong wind advection that inhibits reorganization of the flow characteristics in the upper atmosphere [Sparks et al., 1997]. The flow trajectory in the three bending over stages has been described by empirical relationships [Briggs, 1969; Sparks et al., 1997]:

$$
\begin{array}{cc}
z_{c}=\beta_{1} x_{a}^{2 / 3} & x_{0}<x_{a}<x_{1} \\
z_{c}=\beta_{2} x_{a}^{1 / 2} & x_{1} \leq x_{a}<x_{2} \\
z_{c}=H_{b} & x_{a} \geq x_{2}
\end{array}
$$

where $z_{c}$ is the centerline height and $x_{a}$ is the horizontal downwind position of the centerline measured from the turbulent current source $x_{0}$ (Figure 1b). For simplicity, in our model the turbulent current originates at the vent and therefore $x_{0}=0 . \beta_{1}$ and $\beta_{2}$ are two empirical constants (e.g., $2.5 \mathrm{~m}^{1 / 3}$ and $2.1 \mathrm{~m}^{1 / 2}$ respectively for the 22 July 1980 bentover plume of Mount St. Helens [Sparks et al., 1997]), $H_{b}$ is the height of neutral buoyancy, and $x_{1}$ and $x_{2}$ are the horizontal distances from the vent to the boundary between these three regions:

$$
\begin{aligned}
& x_{1}=\left(\frac{\beta_{2}}{\beta_{1}}\right)^{6}, \\
& x_{2}=\left(\frac{H_{b}}{\beta_{2}}\right)^{2} .
\end{aligned}
$$

[16] A weak plume can be either analyzed as a wellmixed turbulent current or as a current characterized by a double-vortex structure normal to the streamline, dependent on the relative magnitude of turbulent diffusion and the rate 


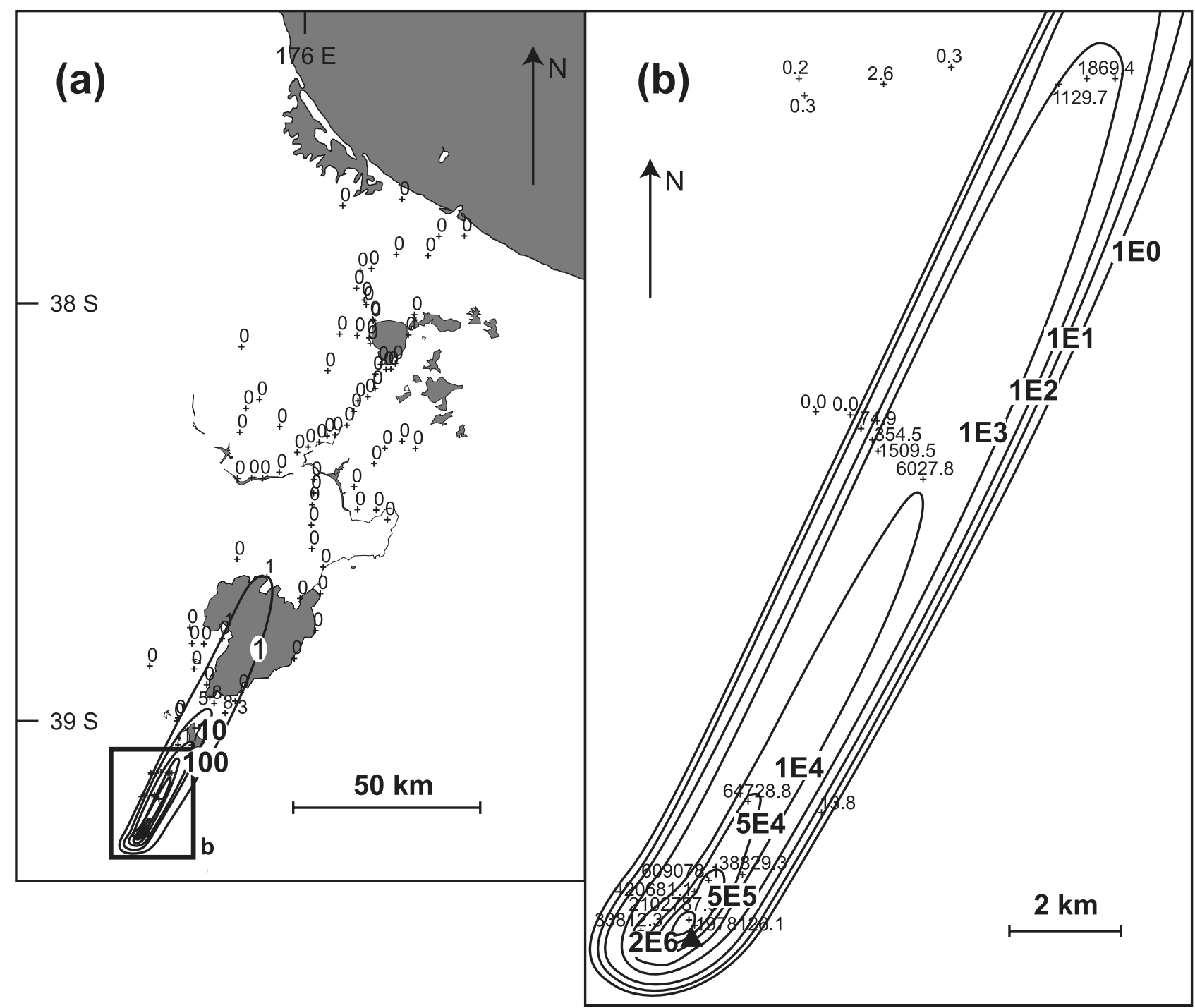

Figure 6. Isomass map of particles with diameter $>1 \mathrm{~mm}$ with two magnifications showing (a) the total and (b) the proximal deposit (in $\mathrm{g} \mathrm{m}^{-2}$ ). In Figure $6 \mathrm{~b}$ isoline values are indicated by scientific notation (e.g., $1 \mathrm{E} 1=10 \mathrm{~g} \mathrm{~m}^{-2}$ ). See color version of this figure in the HTML.

of increase of the plume radius [Turner, 1973]. If the buoyant fluid and the vorticity mix across the center of the current, a linear increase of the plume radius with height is obtained. We define this case as a well-mixed weak plume, and we show that analysis based on buoyant horizontal (gravity current) propagation and diffusion can be used. However, if the vorticity remains concentrated at the plume edges, the vorticity circulation remains constant with time, and the plume radius increases exponentially with height. This case is here defined as a pair-vortex weak plume, and an analysis based on conservation of vorticity is more appropriate [Turner, 1973].

[17] The dynamics of a well-mixed weak plume rising in a uniform environment differs from that of a subvertical strong plume primarily because the dominant velocity shear is nearly perpendicular to the plume axis, rather than parallel to it. This results in a more efficient turbulent mixing, which is reflected in the empirically determined entrainment constant being five times larger than the entrainment constant for a strong plume, $\alpha_{T}=0.5$ for a "top hat" profile [Briggs,
1969] and $\alpha_{G}=0.35$ for a Gaussian profile (defined as $\alpha_{G}=$ $2^{-0.5} \alpha_{T}$; [Turner, 1973]). From dimensional analysis coupled with experimental observations, equation (1a) can also be written as [Briggs, 1969]

$$
z_{c}=1.6 F^{1 / 3} u_{a}^{-1} x_{a}^{2 / 3},
$$

where $F$ is the total buoyancy flux $\left(\mathrm{m}^{4} \mathrm{~s}^{-3}\right)$ and $u_{a}$ is the wind speed $\left(\mathrm{m} \mathrm{s}^{-1}\right)$, supposed constant with height.

[18] The dynamics of a bent-over plume rising in a nonuniform environment cannot be described by existing theory [Turner, 1973]. However, for the low heights typical of weak plumes $(<10 \mathrm{~km})$, a uniform environment can be assumed, because the atmosphere is not strongly stratified [Sparks et al., 1997], and the set of equations (1) to (3) can be used.

\subsection{Particle Distribution at the Base of the Bent-Over Plume}

[19] Sedimentation from a well-mixed weak plume can be described as for sedimentation from strong plumes, model- 


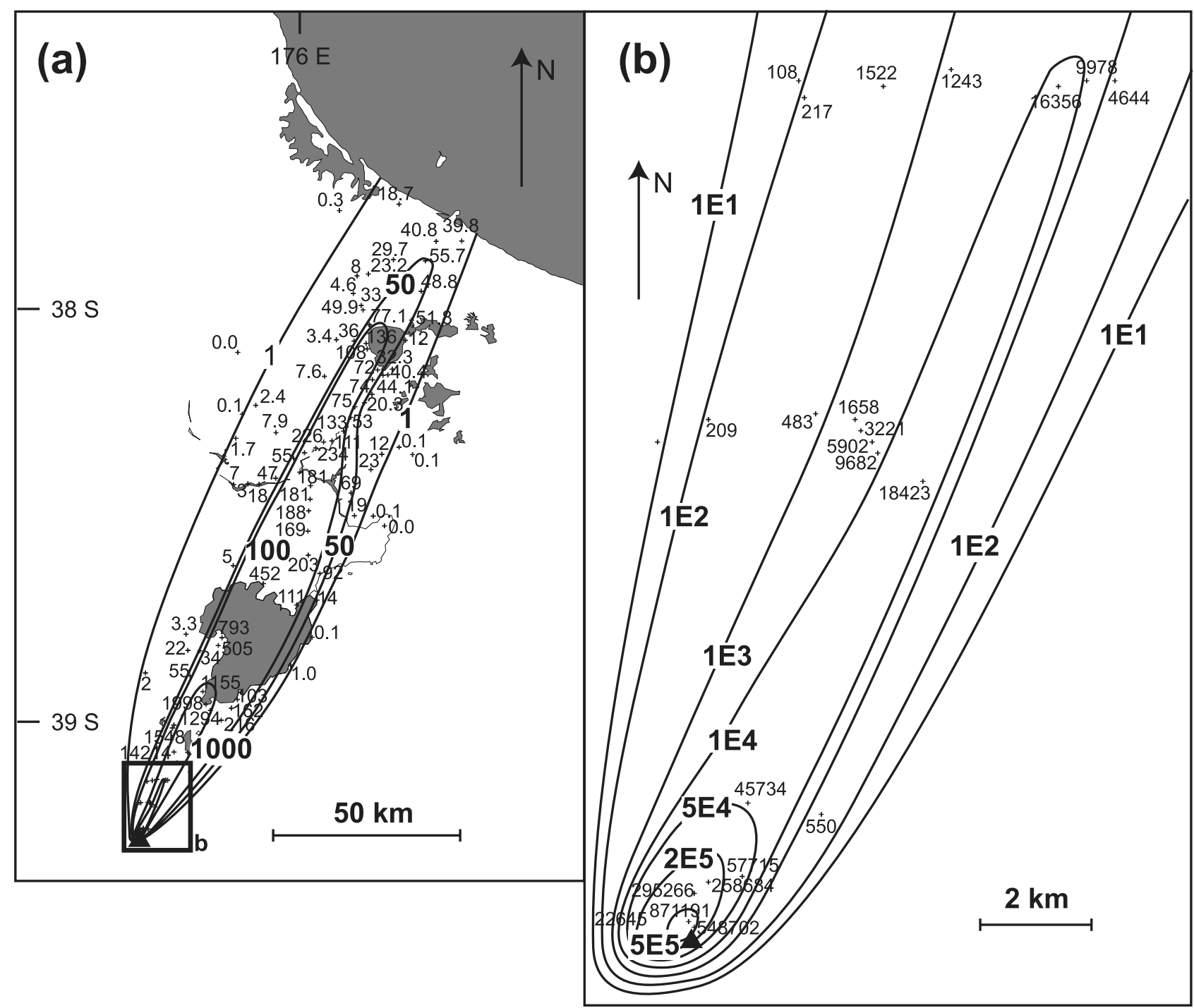

Figure 7. Isomass map of particles with diameter $1 \mathrm{~mm}$ to $125 \mu \mathrm{m}$ with two magnifications showing (a) the total and (b) the proximal deposit (in $\mathrm{g} \mathrm{m}^{-2}$ ). In Figure $7 \mathrm{~b}$, isoline values are indicated by scientific notation (e.g., $1 \mathrm{E} 1=10 \mathrm{~g} \mathrm{~m}^{-2}$ ). See color version of this figure in the HTML.

ing the whole rising plume as a turbulent-diffused current [Turner, 1973], in which the flow and particle distribution are assumed to be homogenized in the vertical direction due to turbulence and vorticity.

[20] To describe particle fall from the base of a bent-over plume, the models for sedimentation from gravity currents by Bursiket al. [1992a] and Bonadonna and Phillips [2003] have been developed. These models are based on the following main assumptions: (1) the atmosphere in which the eruptive plume develops is continuously stratified; (2) the volume flux in the spreading current is constant with distance (i.e., there is no air entrainment into the spreading current); (3) the wind field at the spreading current level is constant in direction and speed; (4) the wind direction along the fall trajectory of the particles is constant; (5) particles are vertically well-mixed by turbulence in the spreading current; (6) the concentration of particles in the crosswind direction of the spreading current has a Gaussian distribution; (7) particles fall out from the bottom of the spreading current where turbulence diminishes and the vertical velocity is negligible. In this model we retain the assumptions 3 to 7 but we also assume a plume developing in a uniform environment and spreading with an increasing volumetric flux due to air entrainment until its trajectory becomes horizontal. We also assume that the wind direction along the plume rise is constant.

[21] Under these conditions, the total mass of particles, $M(\mathrm{~kg})$, of a given size fraction between the turbulent current source, $x_{0}(\mathrm{~m})$, and a distance $x_{a}(\mathrm{~m})$ at the base of the spreading current is [Bursik et al., 1992b]

$$
M=M_{0} \exp -\left\{\int_{x_{o}}^{x_{a}} \frac{v w}{Q} d x\right\},
$$

where $M_{0}(\mathrm{~kg})$ is the initial mass injected into the current, $v\left(\mathrm{~m} \mathrm{~s}^{-1}\right)$ is the particle terminal velocity, $w(\mathrm{~m})$ is the maximum crosswind width of the spreading current at the source and $Q\left(\mathrm{~m}^{3} \mathrm{~s}^{-1}\right)$ is the volumetric flow rate within the current.

[22] The maximum width $w(\mathrm{~m})$ of a well-mixed weak plume spreading laterally by turbulent diffusion can be 


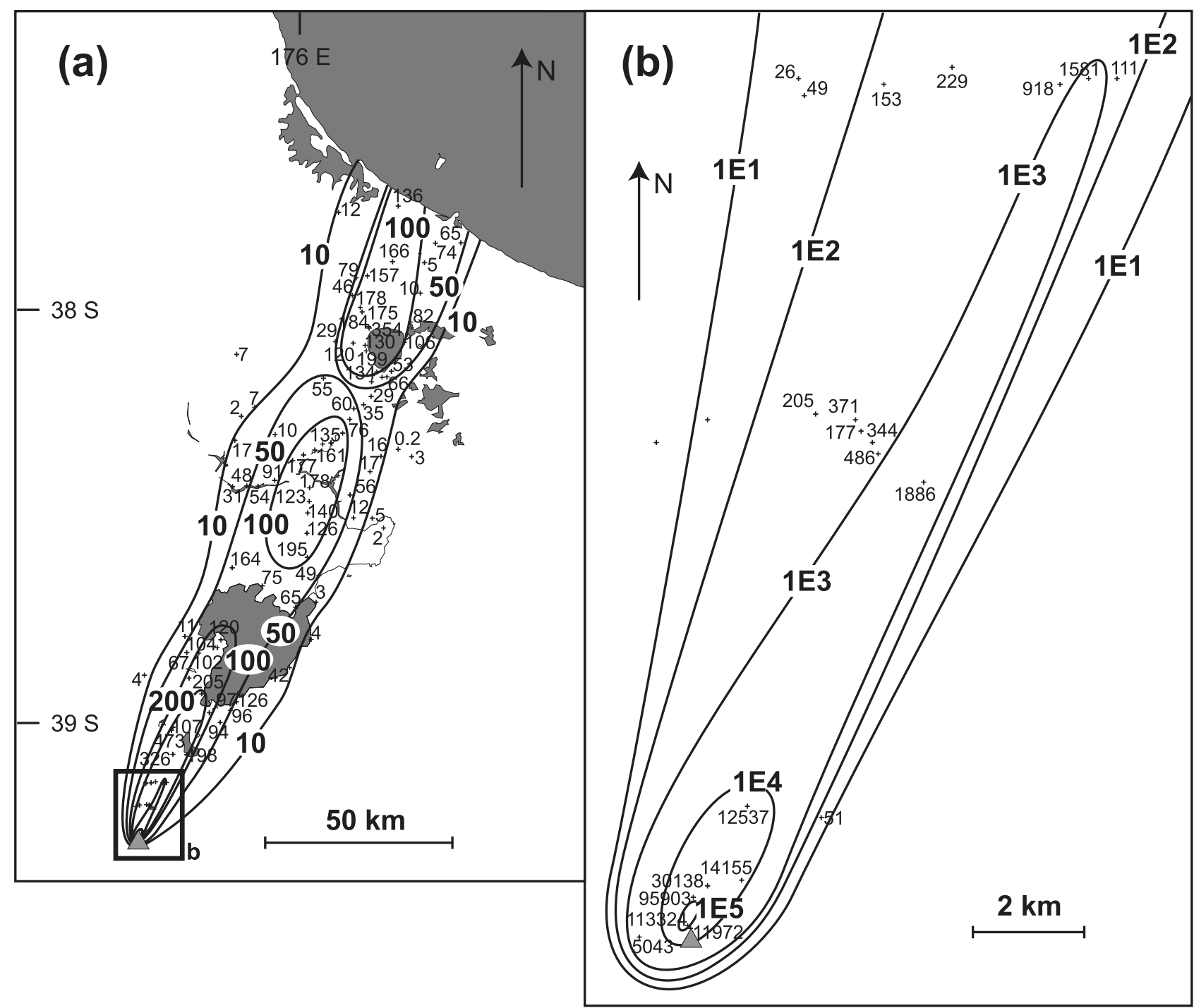

Figure 8. Isomass map of particles with diameter $<125 \mu \mathrm{m}$ with two magnifications showing (a) the total and (b) the proximal deposit (in $\mathrm{g} \mathrm{m}^{-2}$ ). In Figure $8 \mathrm{~b}$ isoline values are indicated by scientific notation (e.g., $1 \mathrm{E} 1=10 \mathrm{~g} \mathrm{~m}^{-2}$ ). See color version of this figure in the HTML.

determined by the Fickian law of diffusion [Bursik, 1998; Sparks et al., 1997]:

$$
w=4 \sqrt{\frac{k x}{u_{a v}}},
$$

where $k\left(\mathrm{~m}^{2} \mathrm{~s}^{-1}\right)$ is the diffusion coefficient, and $u_{a v}\left(\mathrm{~m} \mathrm{~s}^{-1}\right)$ is the wind velocity averaged over the height of plume rise. The total mass of particles, $M(\mathrm{~kg})$, of a given size fraction carried by the spreading turbulent current between $x_{0}$ and $x_{a}$ can then be written as

$$
M=M_{0} \exp -\left\{-4 v \sqrt{\frac{k}{u_{a v}}} \int_{x_{o}}^{x_{a}} \frac{\sqrt{x}}{Q} d x\right\} .
$$

[23] The volumetric flux in a bent-over plume cannot be assumed constant as for the derivation of mass flux of strong-plume currents [Bonadonna and Phillips, 2003] because it increases with distance from the vent due to the effect of turbulent mixing with the atmosphere [Briggs, 1969]:

$$
Q=\alpha^{2} u_{a v} z_{c}^{2},
$$

where $\alpha$ is the entrainment constant for weak plumes (with the "top hat" or "Gaussian" value depending on the distribution profile considered). When the plume starts spreading subhorizontally, the volumetric flux is assumed constant at its maximum value. Using equation (1), the volumetric flux in equation (7) can be written as

$$
\begin{array}{cl}
Q=\alpha^{2} \beta_{1}^{2} u_{a v} x_{a}^{4 / 3}=\varpi_{1} u_{a v} x_{a}^{4 / 3} & x_{0}<x_{a}<x_{1} \\
Q=\alpha^{2} \beta_{2}^{2} u_{a v} x_{a}=\varpi_{2} u_{a v} x_{a} & x_{1} \leq x_{a}<x_{2} \\
Q=\varpi_{2} u_{a v} x_{2}=Q_{\max } & x_{a} \geq x_{2}
\end{array}
$$


with $\varpi_{1}=\alpha^{2} \beta_{1}^{2}$ and $\varpi_{2}=\alpha^{2} \beta_{2}^{2}$, and $x_{1}$ and $x_{2}$ defined as in equation (2).

[24] The total mass of particles of a given size fraction between $x_{0}$ and $x_{a}$ at the current base can now be written as

$$
\begin{aligned}
& M=M_{0} \exp \left\{-\frac{4 v}{\varpi_{1}} \sqrt{\frac{k}{u_{a v}^{3}}} \int_{x_{0}}^{x_{a}} x^{-5 / 6} d x\right\} \\
& =M_{0} \exp \left\{-B_{1}\left(x_{a}^{1 / 6}-x_{0}^{1 / 6}\right)\right\} \quad x_{0}<x_{a}<x_{1} \\
& M=M_{0} \exp \left\{-\frac{4 v}{\varpi_{2}} \sqrt{\frac{k}{u_{a v}^{3}}} \int_{x_{1}}^{x_{a}} \frac{d x}{\sqrt{x}}\right\} \\
& =M_{0} \exp \left\{-B_{2}\left(x_{a}^{1 / 2}-x_{1}^{1 / 2}\right)\right\} \quad x_{1} \leq x_{a}<x_{2} \\
& M=M_{0} \exp \left\{-\frac{4 v}{Q_{\max }} \sqrt{\frac{k}{u_{a v}}} \int_{x_{2}}^{x_{a}} \sqrt{x} d x\right\} \\
& =M_{0} \exp \left\{-B_{3}\left(x_{a}^{3 / 2}-x_{2}^{3 / 2}\right)\right\} \quad x_{a} \geq x_{2}
\end{aligned}
$$

where $B_{1}=\frac{24 v}{\varpi_{1}} \sqrt{\frac{k}{u_{a v}^{3}}}, B_{2}=\frac{8 v}{\varpi_{2}} \sqrt{\frac{k}{u_{a v}^{3}}}, B_{3}=\frac{8 v}{3 Q_{\max }} \sqrt{\frac{k}{u_{a v}}}$. The mass per unit distance, $m_{c b}\left(x, H_{c b}\right)\left(\mathrm{kg} \mathrm{m}^{-1}\right)$, between $x_{0}$ and $x_{a}$ at the base of the spreading current $H_{c b}$, can now be written as

$$
\begin{array}{rlr}
m_{c b}\left(x_{a}, H_{c b}\right)= & \frac{d\left(M_{0}-M\right)}{d x}=\frac{M_{0} v w}{Q} \\
& \cdot \exp \left\{-B_{1}\left(x_{a}^{1 / 6}-x_{0}^{1 / 6}\right)\right\} \quad x_{0}<x_{a}<x_{1} \\
m_{c b}\left(x_{a}, H_{c b}\right)= & \frac{d\left(M_{0}-M\right)}{d x}=\frac{M_{0} v w}{Q} \\
& \cdot \exp \left\{-B_{2}\left(x_{a}^{1 / 2}-x_{1}^{1 / 2}\right)\right\} & \\
m_{c b}\left(x_{a}, H_{c b}\right)= & \frac{d\left(M_{0}-M\right)}{d x}=\frac{M_{0} v w}{Q} \\
& \cdot \exp \left\{-B_{3}\left(x_{a}^{3 / 2}-x_{2}^{3 / 2}\right)\right\} &
\end{array}
$$

[25] Following Bonadonna and Phillips [2003], the mass per unit area at the base of the spreading current, $m_{a}\left(x_{a}, y_{a}\right.$, $\left.H_{c b}\right)\left(\mathrm{kg} \mathrm{m}^{-2}\right)$, can be calculated assuming a Gaussian particle distribution in the crosswind direction of the current:

$$
m_{a}\left(x_{a}, y_{a}, H_{c b}\right)=m_{c b} \frac{\exp \left(-\frac{y_{a}^{2}}{b^{2}}\right)}{b \sqrt{\pi}}
$$

where $b$ is a characteristic length proportional to the effective radius of the maintained plume, i.e., distance from the plume axis at which the velocity or density deficiency have fallen to $c \%$ of the axial value, where $c$ is small [Morton et al., 1956]. By taking $c=1 \%$ the effective radius of the maintained plume is $\approx 2 b$ [Morton et al., 1956]. From equation (5) and from the consideration that $w \approx 4 b$ [Morton et al., 1956], we can also write

$$
b=\sqrt{\frac{k x}{u_{a v}}} .
$$

Therefore the mass per unit area of each particle size accumulated between $x_{0}$ and $x_{a}$ at the base of the spreading current is

$$
\begin{aligned}
& m_{a}\left(x_{a}, y_{a}, H_{c b}\right)=\frac{4 M_{0} v}{Q \sqrt{\pi}} \exp \left\{-B_{1}\left(x_{a}^{1 / 6}-x_{0}^{1 / 6}\right)-\frac{y_{a}^{2}}{b^{2}}\right\} \\
& x_{0}<x_{a}<x_{1} \\
& m_{a}\left(x_{a}, y_{a}, H_{c b}\right)=\frac{4 M_{0} v}{Q \sqrt{\pi}} \exp \left\{-B_{2}\left(x_{a}^{1 / 2}-x_{1}^{1 / 2}\right)-\frac{y_{a}^{2}}{b^{2}}\right\} \\
& x_{1} \leq x_{a}<x_{2} \\
& m_{a}\left(x_{a}, y_{a}, H_{c b}\right)=\frac{4 M_{0} v}{Q \sqrt{\pi}} \exp \left\{-B_{3}\left(x^{3 / 2}-x_{2}^{3 / 2}\right)-\frac{y_{a}^{2}}{b^{2}}\right\} \\
& x_{a} \geq x_{2}
\end{aligned}
$$

The total mass per unit area is the sum of the accumulation of all particle sizes:

$$
m_{a T}\left(x_{a}, y_{a}, H_{c b}\right)=\sum m_{a}\left(x_{a}, y_{a}, H_{c b}\right)
$$

\subsection{Particle Sedimentation From the Plume}

[26] A model of sedimentation from a weak plume must account for wind transport after particles leave the plume. In fact, a particle falling from the current base at a point $\mathrm{A}$ with distance $x_{a}$ from vent is likely to reach the ground at a distance $x_{b}$ from vent, where $x_{b}=x_{a}+x_{w}$ and $x_{w}$ is the distance due to wind transport (Figure 1). The sedimentation of a given particle size class at $x_{b}$ corresponds to the accumulation of the same particle size category at the base of the current at $x_{a}$ (Figure 1). The height $z^{\prime}$ of the current base $H_{c b}$ of a weak plume is described consistently with respect to the trajectory of the plume centerline in equation (1) as

$$
\begin{array}{lc}
z^{\prime}=\beta_{1}^{\prime} x_{a}^{2 / 3} & x_{0}<x_{a}<x_{1} \\
z^{\prime}=\beta_{2}^{\prime} x_{a}^{1 / 2} & x_{1} \leq x_{a}<x_{2} \\
z^{\prime}=0.6 H_{t} & x_{a} \geq x_{2}
\end{array}
$$

where $\beta_{1}^{\prime}$ and $\beta_{2}^{\prime}$ are empirical constants and $\mathrm{H}_{\mathrm{t}}$ is the maximum column height. Equation $15 \mathrm{c}$ is derived from Briggs [1975] with a likely error of $\pm 0.5 \mathrm{~km}$ [Prata and Grant, 2001].

[27] The distance $x_{b}$ can be determined as the intersection between the current base $H_{c b}$ and the particle fall trajectory $\lambda$ (Figure 1b), defined as

$$
z_{p}=-p x+p x_{b}
$$


where $z_{p}$ is the particle fall height at each distance $x$, with $x_{a}<x<x_{b}$, and $p=\frac{v_{a v}^{\prime}}{u^{\prime}}$, where $u_{a v}^{\prime}$ and $v_{a v}^{\prime}$ are the wind velocity and the particlev terminal velocity averaged along the particle fall and kept constant for simplicity. Under this assumption, particles of a given size will fall with a constant angle $\Delta$, where $p=\tan \Delta$ (Figure 1b). From the combination of equations (15) and (16) for $z_{p}=z^{\prime}=H_{c b}$, the distance $x_{a}$ is given by

$$
x_{a}=\frac{\beta_{1}^{\prime}\left(\left(\frac{1}{6} \frac{\Lambda}{p^{2}}\right)+\frac{\frac{2}{3} \beta_{1}^{\prime}\left(6 x_{b} p^{3}+\beta_{1}^{\prime 3}\right)}{\Lambda p^{2}}+\frac{\frac{2}{3} \beta_{1}^{2}}{p^{2}}\right)+x_{b} p}{p} \quad x_{0}<x_{b}<x_{1}
$$

$$
\begin{gathered}
\text { with } \Lambda=\left(72 x_{b} \beta_{1}^{\prime 3} p^{3}+108 x_{b}^{2} p^{6}+8 \beta_{1}^{\prime 6}+\right. \\
\left.12 x_{b} p^{5} \sqrt{3 x_{b}\left(4 \beta_{1}^{\prime 3}+27 x_{b} p^{3}\right) / p}\right)^{1 / 3} \\
x_{a}=\left(\frac{-\beta_{2}^{\prime}+\sqrt{\beta_{2}^{\prime 2}+4 p^{2} x_{b}}}{2 p}\right)^{2} \quad x_{1} \leq x_{b}<x_{2} \quad \text { (17b) } \\
x_{a}=\frac{0.6 H_{t}}{p} \quad x_{b} \geq x_{2} \quad \text { (17c) }
\end{gathered}
$$

for the three zones of the plume trajectory.

[28] The accumulation of particles of a given size at a distance $x_{b}$ is

$$
S\left(x_{b}, y_{a}, 0\right)=m_{a}\left(x_{a}, y_{a}, 0\right),
$$

with $x_{b}-x_{a}=x_{w}$ in Figure $1 \mathrm{~b}$. The total mass of particles accumulated per unit area at a distance $x_{b}$ is the sum of the accumulation of all particle sizes at $x_{b}$ :

$$
S_{T}\left(x_{b}, y_{a}, 0\right)=\sum S\left(x_{b}, y_{a}, 0\right) .
$$

\section{Results}

[29] The preceding model development is based on empirical description of the plume rise, so the model requires input from field observations for the constants of plume rise, $\beta_{1}, \beta_{2}, \beta_{1}^{\prime}$ and $\beta_{2}^{\prime}$. We have tested the model performance by simulating tephra sedimentation from the weak plume generated during the Ruapehu eruption for which good observations of the proximal plume trajectory were made. Results of tephra dispersal modeling in one and two dimensions are presented and discussed in terms of variations with distance from vent of mass accumulation per unit area at the current base $\left(\mathrm{m}_{\mathrm{aT}}\right)$ and ground sedimentation per unit area $\left(\mathrm{S}_{\mathrm{T}}\right)$.

[30] The trajectory of the Ruapehu bent-over plume could be studied in detail within $10 \mathrm{~km}$ from the vent (Figure 9a). The best fit to the centerline and the current base trajectory are given by

$$
\begin{gathered}
z_{c}=15.6 x_{a}^{3 / 5}, \\
z^{\prime}=7.3 x_{a}^{3 / 5} .
\end{gathered}
$$

The discrepancy with the previously identified empirical forms of the weak-plume trajectory given by equation (1) is probably due to the assumption of constant wind velocity, whereas during the Ruapehu eruption the wind velocity varied significantly with height (i.e., $13-34 \mathrm{~m} \mathrm{~s}^{-1}$ between 3-9 km asl; radiosonde data [Prata and Grant, 2001]). In fact, the plume trajectory can be conveniently fitted as

$$
\begin{aligned}
& z_{c}=36.9 x_{a}^{1 / 2}, \\
& z^{\prime}=18.1 x_{a}^{1 / 2},
\end{aligned}
$$

without a significant loss of accuracy (dashed line in Figure $9 \mathrm{~b}$ ). The maximum plume height was determined from satellite images as $8.5 \mathrm{~km}$ [Prata and Grant, 2001]. Substituting equation (20a) in equation (7) with the entrainment constant for the Gaussian profile assumption [Briggs, 1969], we can find the volumetric flux $Q$ :

$$
Q=167 u_{a v} x_{a}
$$

Equations (20) and (21) are assumed to hold for the entire plume trajectory until the plume starts spreading horizontally at the neutral buoyancy level. We can use these approximations to relate the sedimentation rate at the ground at a distance $x_{b}$ from vent to the sedimentation flux at the base of the current at a distance $x_{a}$,

$$
\begin{gathered}
x_{a}=\left(\frac{-18.1-\sqrt{327.6-4 p^{2} x_{b}}}{2 p}\right)^{2} \quad x_{0}<x_{b}<x_{2} \\
x_{a}=\frac{5100}{p} \quad x_{b} \geq x_{2}
\end{gathered}
$$

where $x_{2}$ is the distance where the plume starts spreading horizontally (equation (2)), $p=\frac{v_{a v}^{\prime}}{u_{\alpha v}^{\prime}}$, and $u_{a v}^{\prime} \cong 20 \mathrm{~m} \mathrm{~s}^{-1}$ (i.e., average wind velocity between the current base and the ground between 0830 and 1930; radiosonde data).

[31] We can also estimate the diffusion coefficient for the Ruapehu plume from its trajectory, from the definition of $b$ during plume rise [Morton et al., 1956]:

$$
b=\frac{6}{5} \alpha z_{c}=\frac{6}{5} \alpha 36.9 x_{a}^{1 / 2},
$$

so combining equation (12) with equation (23) we have

$$
k=\left(\frac{6}{5} \alpha 36.9\right)^{2} u_{a v} \approx 5765 \mathrm{~m}^{2} \mathrm{~s}^{-1} .
$$

Figure 10 shows the theoretical width calculated with equation (5) for different values of $k$ and the observed values for (1) deposit width between 3 and $200 \mathrm{~km}$ from vent (width of zero line in Figure 4), (2) plume maximum width between 43 and $936 \mathrm{~km}$ from vent calculated from satellite images (Figure 2), (3) plume vertical thickness between 0.3 and $8.6 \mathrm{~km}$ from vent calculated from Figure $9 \mathrm{a}$ and maximum width of isomass contours between 0.3 and 

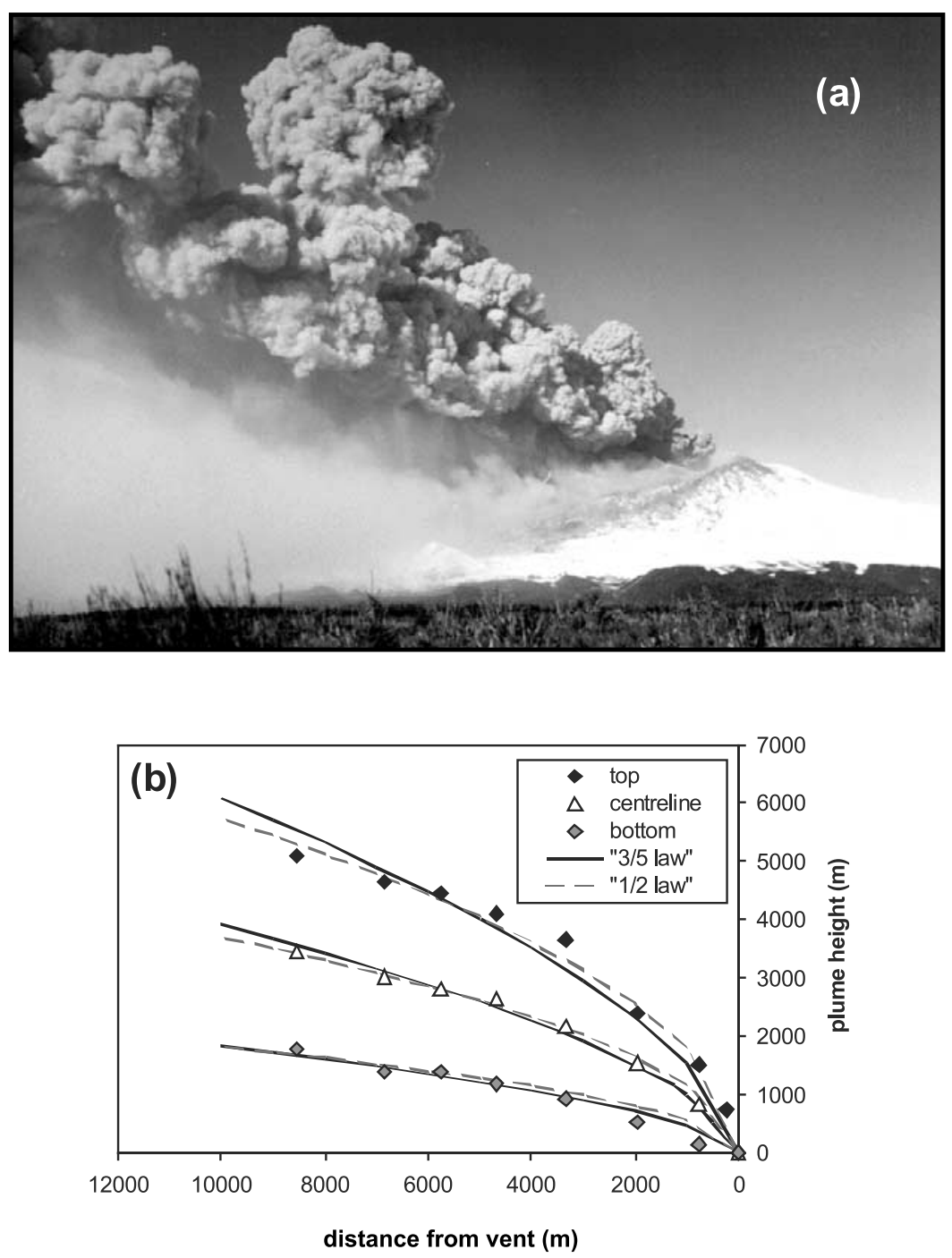

Figure 9. Weak plume generated by the Ruapehu eruption. (a) Photo taken at 1200 at a distance of about $15 \mathrm{~km}$ and on a bearing of about $330^{\circ}$ from the vent (photo B.F. Houghton). (b) Different fits of the trajectory of the top (black diamonds), centerline (white triangles), and base (gray diamonds) of the bent-over plume shown in Figure 9a. The best fit of all points is given by a " $3 / 5$ law" (solid lines; $x=$ $0-8550 \mathrm{~m}$, number of data points $=8,8$, and 9 , and $\mathrm{R}^{2}=0.958,0.993$, and 0.980 for base, centerline, and top respectively). However, for computational convenience, the " $1 / 2$ law" is used in the simulations (dashed lines; $\mathrm{x}=0-8550 \mathrm{~m}$, number of data points $=8,8$, and 9 , and $\mathrm{R}^{2}=0.918,0.992$, and 0.999 for base, centerline, and top, respectively). See color version of this figure in the HTML.

$225 \mathrm{~km}$ from vent (i.e., mass/area range: 3000 to $0.1 \mathrm{~kg} \mathrm{~m}^{-2}$; Figure 4). All observed data show a good agreement with the Fickian law of diffusion, but are characterized by contrasting diffusion coefficients. In Figure 10 the diffusion coefficient is varied to find the best fit of the model (equation (5)) to the field data. Observed deposit and plume width show very large values of $k\left(9 \times 10^{4}\right.$ and $3 \times 10^{4} \mathrm{~m}^{2} \mathrm{~s}^{-1}$ respectively), whereas $k$ values for the proximal plume vertical thickness and the isoline width are of the order of $10^{2}$ and $10^{3} \mathrm{~m}^{2} \mathrm{~s}^{-1}$. Crosswind expansion during bifurcation (beyond $800 \mathrm{~km}$ from vent) cannot be described by a " $x$ 1/2 law" (Fickian diffusion), and is proportional to $x^{3}$ (white circles in Figure 10). The width of isomass contours shows a small $k$ value for the proximal deposit (up to $23 \mathrm{~km}$ ) and a larger value (close to $k$ from equation (24)) for the distal deposit (between 50 and $225 \mathrm{~km}$ from vent) (Figure 10). Unfortunately, there are no satellite data and land observations available for the same range of distances from vent, so we cannot compare observed vertical thickness and lateral expansion of the plume over its entire length. However, the vertical thickness gives a good agreement with $k$ obtained from equation (24), suggesting that at least proximal crosswind spreading and vertical thickness of the plume are roughly equivalent (Figure 10).

\subsection{One-Dimensional Variation of $m_{\mathrm{aT}}$ and $\mathrm{S}_{\mathrm{T}}$ With Distance From Vent: Runs 1-4 in Table 1}

[32] Simulations of the Ruapehu deposit were made using the Gaussian fit of the total grain size distribution deter- 


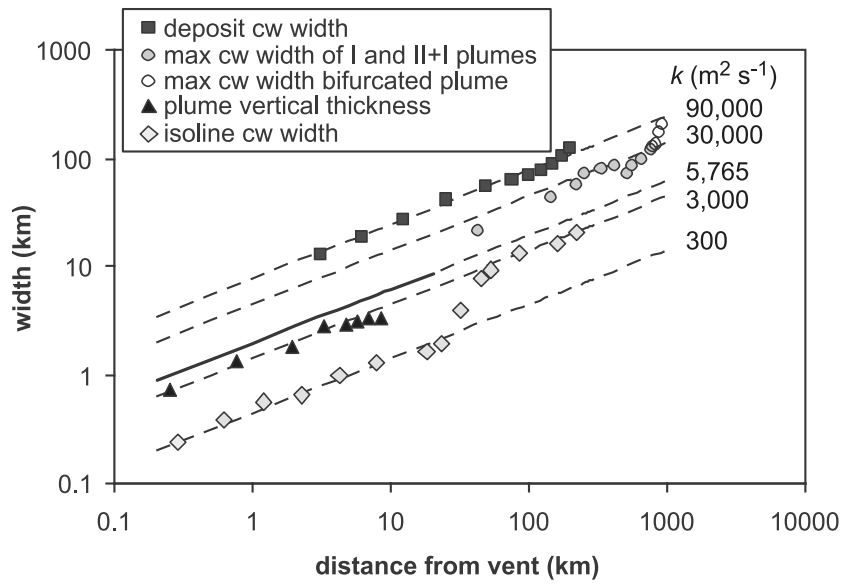

Figure 10. Logarithmic plot showing the crosswind spreading of the plume (gray and white circles), the lateral extension of the deposit (red squares), the proximal vertical thickness of the plume (black triangles) and the width of isolines from the isomass map in Figure 4 (gray diamonds). Corresponding best fit trends of Fickian diffusion calculated from equation (5) with different diffusion coefficients are also shown (coefficients are shown in $\mathrm{m}^{2} \mathrm{~s}^{-1}$ next to the corresponding dashed line). The solid line represents the calculation of the plume width by using the theory by Morton et al. [1956] in equation (24). See color version of this figure in the HTML.

mined by Bonadonna and Houghton [2005], coupled with the density model from Bonadonna and Phillips [2003] (Figure 11 and Table 1). The Gaussian fit is necessary in order to have a large number of size classes that can smooth the effect of wind fractionation on the ground [Bonadonna and Phillips, 2003]. Figure 12a shows the variation with distance from vent of (1) computed mass accumulation at the current base (run 1; $\mathrm{m}_{\mathrm{aT}}$ ), (2) computed sedimentation on ground (run 2; $\mathrm{S}_{\mathrm{T}}$ ) and (3) observed mass accumulation (from Houghton et al., submitted manuscript, 2005). The trajectory of the simulated plume is also shown (thick line) referred to the secondary axis. Values of mass/area are computed at distances from vent for which observed mass/area values are also available (Figure 4). A diffusion coefficient of $3 \times 10^{4} \mathrm{~m}^{2} \mathrm{~s}^{-1}$ is used for the whole plume trajectory, in agreement with the plume crosswind spreading recorded on the JMA satellite images (Figures 2 and 10). The simulated mass accumulation at the current base shows a secondary maximum at the transition between bent-over and horizontal spreading of the plume ( $27 \mathrm{~km}$ from vent) that corresponds to a transition in the accumulation law (see equation (13)). In the bent-over stage of plume rise, the mass flux is proportional to $\sim \exp \left(-x^{1 / 2}\right)$ and the volumetric flux varies linearly with $x$ (equation (21)). When the plume starts spreading horizontally, the mass flux is proportional to $\sim \exp \left(-x^{3 / 2}\right)$ and the volumetric flux is constant at its maximum value. In this simulation, the plume is assumed to spread horizontally around the neutral buoyancy level calculated as $H_{b}=0.7 H_{t} \cong 6 \mathrm{~km}$ (with $H_{t}=8.5 \mathrm{~km}$ [Prata and Grant, 2001]). Mass accumulation on the ground does not show the mass accumulation maximum shown at the base of the current because particles respond differently to wind transport according to their size and density.

[33] Field data (gray circles) plot in between $\mathrm{m}_{\mathrm{aT}}$ and $\mathrm{S}_{\mathrm{T}}$ suggesting that, during sedimentation, particles were affected by a weaker wind velocity than suggested by the average radiosonde data (i.e., $20 \mathrm{~m} \mathrm{~s}^{-1}$; Figure 12a). To investigate this discrepancy, we define a factor $\gamma$ for the estimated wind speed such that the modeled tephra accumulation matches the measured values; we subsequently refer to this factor as the fall wind factor. Thus the factor $p$ in equations (16) and equation (22) becomes $p=\frac{v_{a v}^{\prime}}{u_{o v}^{\prime} \gamma}$. $\mathrm{S}_{\mathrm{T}}$ computed using $10 \%$ of the estimated average wind ${ }^{\prime a} \gamma$ speed $(\gamma=0.1$; run 4$)$ shows very good agreement with field data beyond $4 \mathrm{~km}$ from vent (i.e., difference between computed and observed mass/area is between 0.02 and $15 \mathrm{~kg} \mathrm{~m}^{-2}$ for an observed mass/area varying between 0.1 and $200 \mathrm{~kg} \mathrm{~m}^{-2}$; Figure 12b) indicating that tephra sedimentation during Ruapehu eruption was nearly vertical, as also confirmed by observations (Figure 9a) (Houghton et al., submitted manuscript, 2005). Our model significantly overestimates the mass/area within $2 \mathrm{~km}$ from vent (difference between computed and observed mass/area is between 200 and $45000 \mathrm{~kg} \mathrm{~m}^{-2}$ for an observed mass/area varying between 500 and $3000 \mathrm{~kg} \mathrm{~m}^{-2}$; Figure 12a), possibly due to the fact that our model does not account for topography and to our approximation of the first stage of plume rise as $z=$ $f\left(x^{1 / 2}\right)$ rather than $z=f\left(x^{2 / 3}\right)$ or $z=f\left(x^{3 / 5}\right)$.

\subsection{Two-Dimensional Variation of $m_{\mathrm{aT}}$ and $S_{\mathrm{T}}$ With Distance From Vent: Runs 5-12 in Table 1}

[34] Equations 14 and 18 allow $\mathrm{m}_{\mathrm{aT}}$ and $\mathrm{S}_{\mathrm{T}}$ to be computed in two dimensions. However, maps computed with a diffusion coefficient of $3 \times 10^{4} \mathrm{~m}^{2} \mathrm{~s}^{-1}$ or $9 \times 10^{4} \mathrm{~m}^{2} \mathrm{~s}^{-1}$ (best fit values for plume crosswind spreading and deposit width respectively; runs 5-6, Figure 10) are significantly narrower than the deposit map (Figure 13), suggesting that the actual crosswind sedimentation decreases less steeply than the sedimentation predicted by model simulations. Therefore an empirical spreading factor $(\varepsilon)$ is introduced

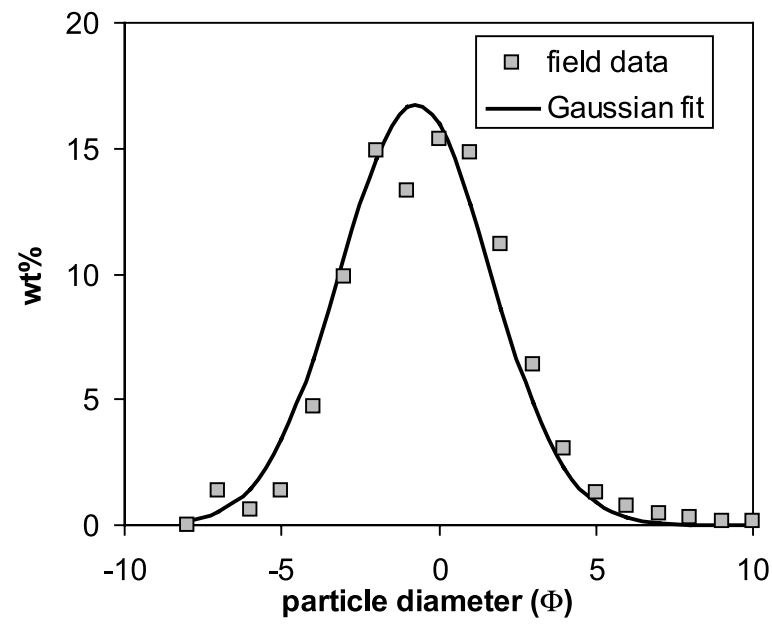

Figure 11. Gaussian best fit (solid line) of the total grain size distribution for the Ruapehu tephra fall deposit determined from field data (squares [from Bonadonna and Houghton, 2005]). 
Table 1. Parameters Used in the Simulations ${ }^{\mathrm{a}}$

\begin{tabular}{|c|c|c|c|c|c|c|c|c|c|c|c|c|}
\hline & Simulation & Figure & Equation & $\begin{array}{c}\text { Column } \\
\text { Height, } \\
\mathrm{m}\end{array}$ & $\begin{array}{c}\text { Vent } \\
\text { Height, } \\
\text { m }\end{array}$ & $\begin{array}{c}\text { Erupted } \\
\text { Mass, } \\
\times 10^{9} \mathrm{~kg} \\
\end{array}$ & $\begin{array}{l}\text { Fall } \\
\text { Wind, } \\
\mathrm{m} \mathrm{s}^{-1}\end{array}$ & $\begin{array}{l}\text { Rise } \\
\text { Wind, } \\
\mathrm{m} \mathrm{s}^{-1}\end{array}$ & $\begin{array}{c}\text { Density } \\
\text { Pumices/Lithics, } \\
\mathrm{kg} \mathrm{m}^{-3}\end{array}$ & $\begin{array}{c}\text { Diffusion } \\
\text { Coefficient, } \\
\mathrm{m}^{2} \mathrm{~s}^{-1}\end{array}$ & $\begin{array}{l}\text { Crosswind } \\
\text { Factor } \varepsilon\end{array}$ & $\begin{array}{c}\text { Fall } \\
\text { Wind } \\
\text { Factor } \gamma\end{array}$ \\
\hline \multicolumn{13}{|c|}{ One-Dimensional Simulations } \\
\hline Run 1 & $\mathrm{~m}_{\mathrm{aT}}$ & 12 & (14) & 8500 & 3000 & 5 & 20 & 24 & $1100-2650$ & 30000 & - & - \\
\hline Run 2 & $\mathrm{~S}_{\mathrm{T}}$ & 12 & (18) & 8500 & 3000 & 5 & 20 & 24 & $1100-2650$ & 30000 & - & 1 \\
\hline Run 3 & $\mathrm{~S}_{\mathrm{T}}$ & 12 & (18) & 8500 & 3000 & 5 & 20 & 24 & $1100-2650$ & 30000 & - & 0.5 \\
\hline Run 4 & $\mathrm{~S}_{\mathrm{T}}$ & 12 & (18) & 8500 & 3000 & 5 & 20 & 24 & $1100-2650$ & 30000 & - & 0.1 \\
\hline \multicolumn{13}{|c|}{ Two-Dimensional Simulations } \\
\hline Run 5 & $\mathrm{~S}_{\mathrm{T}}$ & 13 & (18) & 8500 & 3000 & 5 & 20 & 24 & $1100-2650$ & 30000 & 1 & 0.1 \\
\hline Run 6 & $\mathrm{~S}_{\mathrm{T}}$ & 13 & (18) & 8500 & 3000 & 5 & 20 & 24 & $1100-2650$ & 90000 & 1 & 0.1 \\
\hline \multicolumn{13}{|c|}{ Two-Dimensional Sensitivity Tests } \\
\hline Runs 7 & $\gamma$ & 14 & (18) & 8500 & 3000 & 5 & 20 & 24 & $1100-2650$ & 30000 & 1 & $\mathbf{0 . 0 5}-\mathbf{1} B F: 0.1$ \\
\hline Runs 8 & $\varepsilon$ & 14 & (18) & 8500 & 3000 & 5 & 20 & 24 & $1100-2650$ & 30000 & 1-5; BF: 2.5 & 0.1 \\
\hline Runs 9 & $k$ & 14 & (18) & 8500 & 3000 & 5 & 20 & 24 & $1100-2650$ & $10^{2}-5 \times 10^{6} ; \mathrm{BF}: 35000$ & 2.5 & 0.1 \\
\hline \multicolumn{13}{|c|}{ Two-Dimensional Best Fit Simulations } \\
\hline Run 10 & best fit plot & 15 & (18) & 8500 & 3000 & 5 & 20 & 24 & $1100-2650$ & 35000 & 2.5 & 0.1 \\
\hline Run 11 & $\mathrm{~m}_{\mathrm{aT}}$ & 16 & (14) & 8500 & 3000 & 5 & 20 & 24 & $1100-2650$ & 35000 & 2.5 & 0.1 \\
\hline Run 12 & $\mathrm{~S}_{\mathrm{T}}$ & 16 & (18) & 8500 & 3000 & 5 & 20 & 24 & $1100-2650$ & 35000 & 2.5 & 0.1 \\
\hline
\end{tabular}

${ }^{a}$ Values in bold are the parameters varied to test the sensitivity of the model. Here $m_{a T}$ indicates tephra accumulation at the base of the spreading current. $S_{T}$ indicates tephra sedimentation at the ground. BF is the best fit value. Column height is the maximum height of the eruptive plume (m). Vent height is the height of the eruptive vent $(\mathrm{m})$. Erupted mass is the total mass of tephra erupted $(\mathrm{kg})$. Fall wind is the average wind speed between the base of the spreading current and sea level (i.e., wind along particle fall; radiosonde data [Prata and Grant, 2001]) ( $\mathrm{m} \mathrm{s}^{-1}$ ). Rise wind is the average wind speed between the base of the spreading current and vent height (i.e., wind along plume rise; radiosonde data [Prata and Grant, 2001]) ( $\mathrm{m} \mathrm{s}^{-1}$ ). Density is the measured density of the erupted centimetric clasts $\left(\mathrm{kg} \mathrm{m}^{-3}\right)$; density of all pumice particles is made varied between the density of centimetric pumices and the density of centimetric lithics according to the density model by Bonadonna and Phillips [2003]. Diffusion coefficient is the diffusion coefficient $k$ in equation (5) ( $\mathrm{m}^{2}$ $\mathrm{s}^{-1}$ ). Crosswind factor $(\varepsilon)$ is the parameter used to determine the actual crosswind sedimentation (equation (25)). Fall wind factor $(\gamma)$ is the parameter used to determine the actual wind speed during particle fall.

as for the downwind sedimentation, and equation (13) becomes

$$
\begin{aligned}
& m_{a}\left(x_{a}, y_{a}, H_{c b}\right)=\frac{4 M_{0} v}{Q \sqrt{\pi}} \exp \left\{-B_{1}\left(x_{a}^{1 / 6}-x_{0}^{1 / 6}\right)-\frac{y_{a}^{2}}{(\varepsilon b)^{2}}\right\} \\
& x_{0}<x_{a}<x_{1}
\end{aligned}
$$

$$
\begin{aligned}
& m_{a}\left(x_{a}, y_{a}, H_{c b}\right)=\frac{4 M_{0} v}{Q \sqrt{\pi}} \exp \left\{-B_{2}\left(x_{a}^{1 / 2}-x_{1}^{1 / 2}\right)-\frac{y_{a}^{2}}{(\varepsilon b)^{2}}\right\} \\
& x_{1} \leq x_{a}<x_{2}
\end{aligned}
$$

$$
\begin{aligned}
& m_{a}\left(x_{a}, y_{a}, H_{c b}\right)=\frac{4 M_{0} v}{Q \sqrt{\pi}} \exp \left\{-B_{3}\left(x_{a}^{3 / 2}-x_{2}^{3 / 2}\right)-\frac{y_{a}^{2}}{(\varepsilon b)^{2}}\right\} \\
& \quad x_{a} \geq x_{2}
\end{aligned}
$$

[35] The large data set collected soon after the Ruapehu eruption allowed detailed sensitivity tests to be carried out in order to determine the best fit values for the empirical parameters used (i.e., diffusion coefficient, fall wind factor, crosswind factor). Best fit values were determined using the misfit function $(\mathrm{mf})$, which is a measure of discrepancy between computed and observed data [Bonadonna et al., 2002a], on 89 sample points between $4 \mathrm{~km}$ and $180 \mathrm{~km}$ from vent (runs 7-9 in Table 1). Figure 14 shows that the best fit is obtained for a fall wind factor $(\gamma)$ of 0.1 , a crosswind factor $(\varepsilon)$ of 2.5 and a diffusion coefficient of $3.5 \times 10^{4} \mathrm{~m}^{2} \mathrm{~s}^{-1}\left(m f=0.33 \mathrm{~kg} \mathrm{~m}^{-2}\right.$; number of points = $89 ;$ mass $/$ area $=0.002 \div 11.680 \mathrm{~kg} \mathrm{~m}^{-2}$ ). Both the fall wind factor and the diffusion coefficient fit well with the $1 \mathrm{D}$ investigations of $\mathrm{S}_{\mathrm{T}}$ (Figure 12). Figure 15 shows that our model underestimates the measured accumulation mainly at values between 0.01 and $1 \mathrm{~kg} \mathrm{~m}^{-2}$, probably reflecting the fact that our model cannot reproduce the sinuosity shown by the Ruapehu deposit (Figure 13). Similar results were obtained using the advection-diffusion model TEPHRA but with a higher $m f$ value for the same data set $\left(m f=0.58 \mathrm{~kg} \mathrm{~m}^{-2}\right)$ [Bonadonna et al., 2005].

[36] Figure 16 shows the comparison between the isomass maps computed with the best fit values of $k, \gamma$, and $\varepsilon$ for the accumulation of tephra at the base of the current $\left(\mathrm{m}_{\mathrm{aT}}\right)$ and on the ground $\left(\mathrm{S}_{\mathrm{T}}\right)$ (runs 11 and 12 in Table 1). The most striking feature is the secondary maximum of accumulation between 0.01 and $0.2 \mathrm{~kg} \mathrm{~m}^{-2}$ around $27 \mathrm{~km}$ from the vent shown by the $\mathrm{m}_{\mathrm{aT}}$ map. This maximum is also shown by Figure 12 and corresponds to the change in plume-spreading regime from bent over to horizontal. Such a maximum is not shown by the $S_{T}$ map or by the field data map because particles are dispersed by the wind as soon as they leave the base of the spreading current (Figures 4, 13, and 16b).

[37] Figures 15 and 16 show good agreement between computed and observed data when empirical parameters are used. However, the field data map (Figures 4 and 13c) also shows a much more complex sedimentation pattern than the computed $\mathrm{S}_{\mathrm{T}}$ map (Figure 16b) reflecting complexity of the fall dynamics that is not captured by this simple sedimentation model. The main discrepancy is represented by the pronounced sinuosity of the contours sometimes resulting in double maxima of accumulation. Reasons for this are discussed in the following section.

\section{Discussion}

[38] The rise dynamics of strong and weak plumes have been investigated experimentally and theoretically since the 

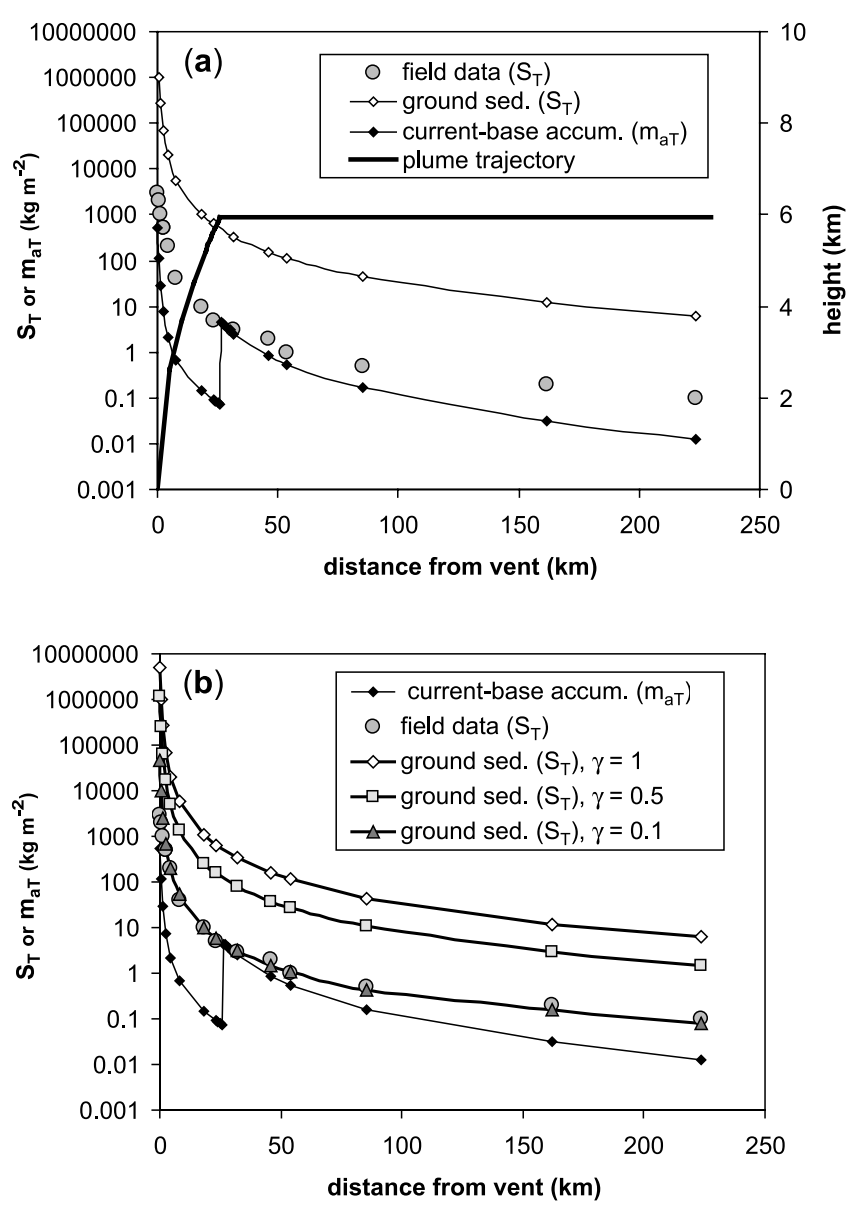

Figure 12. (a) Comparison between computed and observed variation of sedimentation per unit area $\left(\mathrm{S}_{\mathrm{T}}\right)$ and computed accumulation at the current base $\left(\mathrm{m}_{\mathrm{aT}}\right)\left(\mathrm{kg} \mathrm{m}^{-2}\right)$ on a semilog plot versus distance from vent $(\mathrm{km})$ for the Ruapehu tephra deposit. Observed data are indicated with gray circles; computed accumulation at the current base is indicated with black diamonds on a solid line; computed sedimentation on ground is indicated with white diamonds on a solid line (fall wind $=20 \mathrm{~m} \mathrm{~s}^{-1}$ ). Fall wind is the average wind velocity along the trajectory of falling particles. The computed trajectory of the plume centerline is shown on a secondary axis (from equation (20a); thick solid line). (b) Semilog plots showing $\mathrm{S}_{\mathrm{T}}$ variation with distance from vent computed with $50 \%$ and $10 \%$ of the observed fall wind value $(\gamma=0.5$ and 0.1 , i.e., fall wind of 10 and $2 \mathrm{~m} \mathrm{~s}^{-1}$, squares and triangles, respectively). Field data, computed accumulation at the current base, and computed sedimentation on ground for $\gamma=1$ are also shown for comparison. See Table 1 for all the parameters used in the simulations (runs 1-4). See color version of this figure in the HTML.

late 1950s [e.g., Briggs, 1969; Morton et al., 1956; Turner, 1973] and sedimentation from strong plumes has also been studied in detail [e.g., Armienti et al., 1988; Bonadonna and Phillips, 2003; Bursik et al., 1992b; Glaze and Self, 1991; Macedonio et al., 1988; Sparks et al., 1992]. In contrast, the dynamics of weak plumes has only permitted empirical description [e.g., Briggs, 1969; Ernst et al.,
1994, 1996; Fric and Roshko, 1994; Turner, 1973], and the model presented in this paper represents the first attempt to model sedimentation from bent-over plumes making a detailed comparison with field data (from the 17 June 1996 subplinian eruption of Ruapehu, New Zealand).

[39] The spreading of both strong-plume umbrella clouds and well-mixed weak plumes can be described as the spreading of turbulent currents [Turner, 1973]. Sedimentation from these spreading turbulent currents has been described using simple theory by Bursik et al. [1992b] and Bonadonna and Phillips [2003] for which particle settling is opposed by turbulence, so that a gradient of downward increasing particle concentration is established. However, the turbulent currents generated by strong and weak plumes differ in the controls on the current width downwind: spreading of strong-plume currents is directly controlled by density contrasts with the atmosphere, whereas spreading of weak-plume currents is mainly controlled by turbulent diffusion of the atmosphere [Briggs, 1969].

[40] In line with previous studies, the plume rise dynamics are described using empirical constants (e.g., diffusion coefficient and constants of plume rise, $\beta_{1}, \beta_{2}, \beta_{1}^{\prime}$ and $\beta_{2}^{\prime}$ ) and to obtain a reasonable fit to field deposit data, we find that sedimentation also needs to be described using empirical parameters (diffusion coefficient, fall wind and crosswind factors; $k, \gamma$ and $\varepsilon$ in Table 1). The use of empirical parameters is necessary to account for errors in field data (e.g., wind data measured far from plume spreading and difficulties in sampling very thin deposits), but it is also necessary to capture the complexity of the processes described. Errors in field data are difficult to quantify, but we can discuss some of the uncertainties in the descriptions of the physical processes that necessitate the introduction of empirical coefficients.

[41] In the absence of a detailed description of the physical processes controlling weak-plume spreading, we have chosen to model the spreading of the horizontal weak plume current as a Fickian diffusion process (equation (5)). In taking this approach, we acknowledge that we are not explicitly accounting for some processes that may strongly influence the current spreading (1) gravitational spreading due to density contrasts with the atmosphere, (2) enhanced downwind transport of the plume due to much greater entrainment effects in weak plumes as compared with strong plumes, and (3) entrainment into the subhorizontal spreading current. Neglecting the first and last of these processes leads to an underestimation of the turbulent current crosswind spreading, and we find that we need to use a large value for the diffusion coefficient to match observations of the turbulent current width.

[42] The results of this study raise some issues relevant to the application of diffusion models to tephra dispersal modeling. The Fickian diffusion law gives reasonable agreement with the observed crosswind spreading of the Ruapehu plume and the downwind expansion of the Ruapehu deposit (Figure 4). However, the best fit diffusion coefficient for the deposit width $\left(9 \times 10^{4} \mathrm{~m}^{2} \mathrm{~s}^{-1}\right)$ is higher than the observed and computed best fit value for plume lateral expansion $\left(3 \times 10^{4}\right.$ and $3.5 \times 10^{4} \mathrm{~m}^{2} \mathrm{~s}^{-1}$; Figures 12 and 14). Increasing the diffusion coefficient can account 
(a) computed sedimentation at the ground $\left(\mathrm{S}_{\mathrm{T}}\right)$ $D C=30,000 \mathrm{~kg} \mathrm{~m}^{-2}$

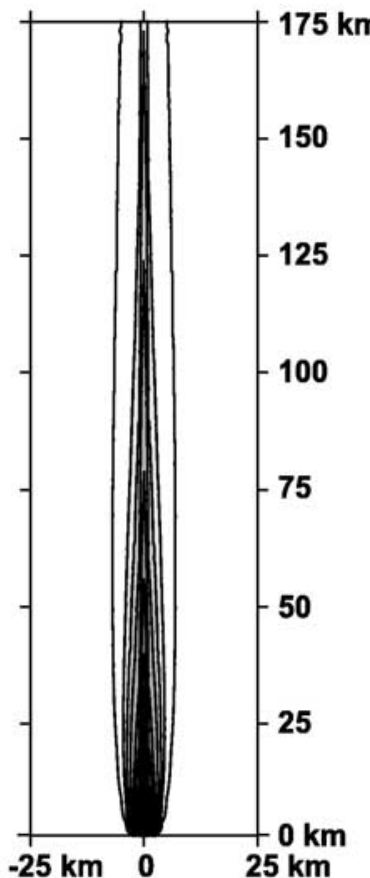

(b) computed sedimentation at the ground $\left(\mathrm{S}_{\mathrm{T}}\right)$ $D C=90,000 \mathrm{~kg} \mathrm{~m}^{-2}$
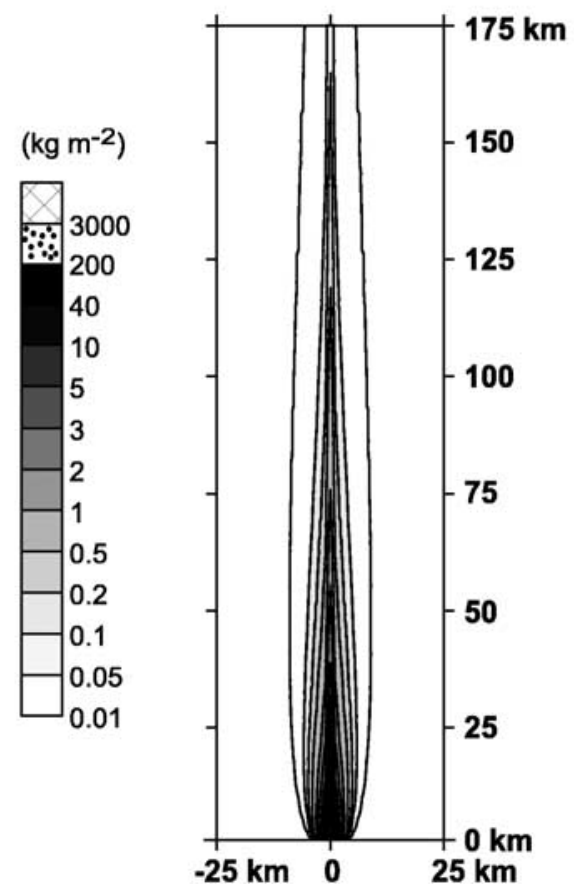

(c) observed sedimentation at the ground $\left(\mathrm{kg} \mathrm{m}^{-2}\right)$

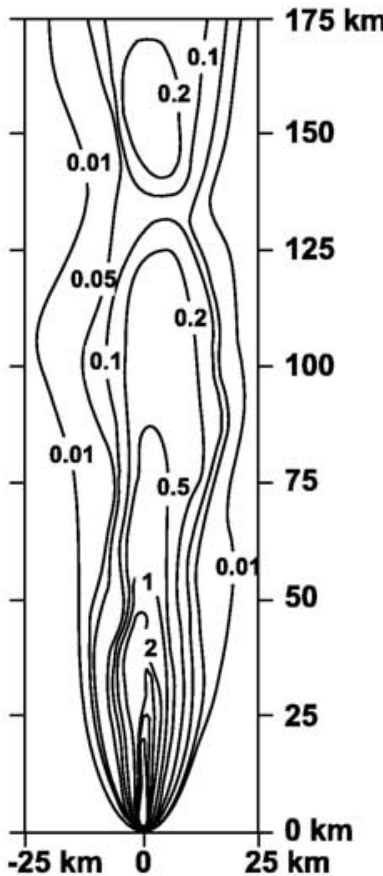

Figure 13. Isomass maps showing (a) $\mathrm{S}_{\mathrm{T}}$ distribution computed using $k=3 \times 10^{4} \mathrm{~m}^{2} \mathrm{~s}^{-1}$, (b) $\mathrm{S}_{\mathrm{T}}$ distribution computed using $k=9 \times 10^{4} \mathrm{~m}^{2} \mathrm{~s}^{-1}$, and (c) observed mass/area from Figure $4\left(\mathrm{~kg} \mathrm{~m}^{-2}\right)$. See Table 1 for parameters used in the simulations (run 5 and 6). Computed data were contoured in agreement with the isolines compiled from the observed data (Figure 4) (Houghton et al., submitted manuscript, 2005).

for the horizontal shift between accumulation at the base of the spreading current and sedimentation on the ground due to crosswind transport of the tephra below the spreading current height. This horizontal shift is also observed in sedimentation from strong plumes [Bonadonna and Phillips, 2003]. Some discrepancy between diffusion coefficients for the observed deposit and plume could also be due to the uncertainties in determining both the deposit "zero line" and the plume margins (Figures 2 and 4). Finally, weak plumes are characterized by a nonuniform entrainment generating an upward motion beneath the centerline and downward motion on the sides [Fric and Roshko, 1994]. This phenomenon can lead to bifurcation but could also broaden the deposit by moving particles from the center of the deposit toward the side (P. Cunningham, personal communication, 2004).

[43] Diffusion models approximate complex and competing processes in a low-order mathematical model, and as such, the value of the diffusion coefficient cannot be related to the details of any one process. In this study, observed and computed diffusion coefficients for Ruapehu are the order of magnitude of those predicted for atmospheric dispersion $\left(10-10^{4} \mathrm{~m}^{2} \mathrm{~s}^{-1}\right)$ [Heffter, 1965; Pasquill, 1974], although they are significantly higher than those typically used in advection-diffusion models (e.g., $3 \times 10^{3} \mathrm{~m}^{2} \mathrm{~s}^{-1}$, Vesuvius [Macedonio et al., 1988]; $6 \times 10^{3} \mathrm{~m}^{2} \mathrm{~s}^{-1}$, Ruapehu [Hurst and Turner, 1999], $2.7 \times 10^{3} \mathrm{~m}^{2} \mathrm{~s}^{-1}$, Montserrat [Bonadonna et al., 2002a]). This discrepancy can be explained by the relative energetics of weak plumes. In fact, the Fickian law of diffusion has been used primarily to describe volcanic plumes when they have lost their density contrast with the atmosphere and are advected as lens of aerosol and gas with nearly constant width, e.g., 22 July 1980 eruption of Mount St. Helens and 3 April 1986 eruption of Augustine [Bursik, 1998; Sparks et al., 1997]. These authors also suggested the application of this diffusion law to plumes that have insufficient energy to form an umbrella cloud and to reach the tropopause.

[44] The dynamics of weak-plume rise is controlled by the energetics of both the plume and the wind field. The Ruapehu plume was more energetic than the last stage of the 22 July 1980 strong plume of Mount St. Helens and the 3 April 1986 very weak and puff-like plume of Augustine. A simple measure of the energetics of a weak plume is the steepness of its trajectory relative to the wind speed. For the Ruapehu eruption, the constant $\beta_{2}$ defined by the relationship $z_{c}=\beta_{2} x^{1 / 2}$ (equation (1b)) is greater than that determined for the 22 July 1980, Mount St. Helens eruption (36.9 and $2.1 \mathrm{~m}^{1 / 2}$ respectively [Sparks et al., 1997]). The mean wind speeds during plume rise were $24 \mathrm{~m} \mathrm{~s}^{-1}$ for the Ruapehu eruption and $15 \mathrm{~m} \mathrm{~s}^{-1}$ for Mount St. Helens (radiosonde data from http://weather.uwyo.edu/), indicating that the Ruapehu plume was more energetic. We conclude that Fickian diffusion can be a good approximation to the crosswind spreading of both "vigorous" and "low-energy" weak plumes, but a wide range of diffusion coefficients is to 

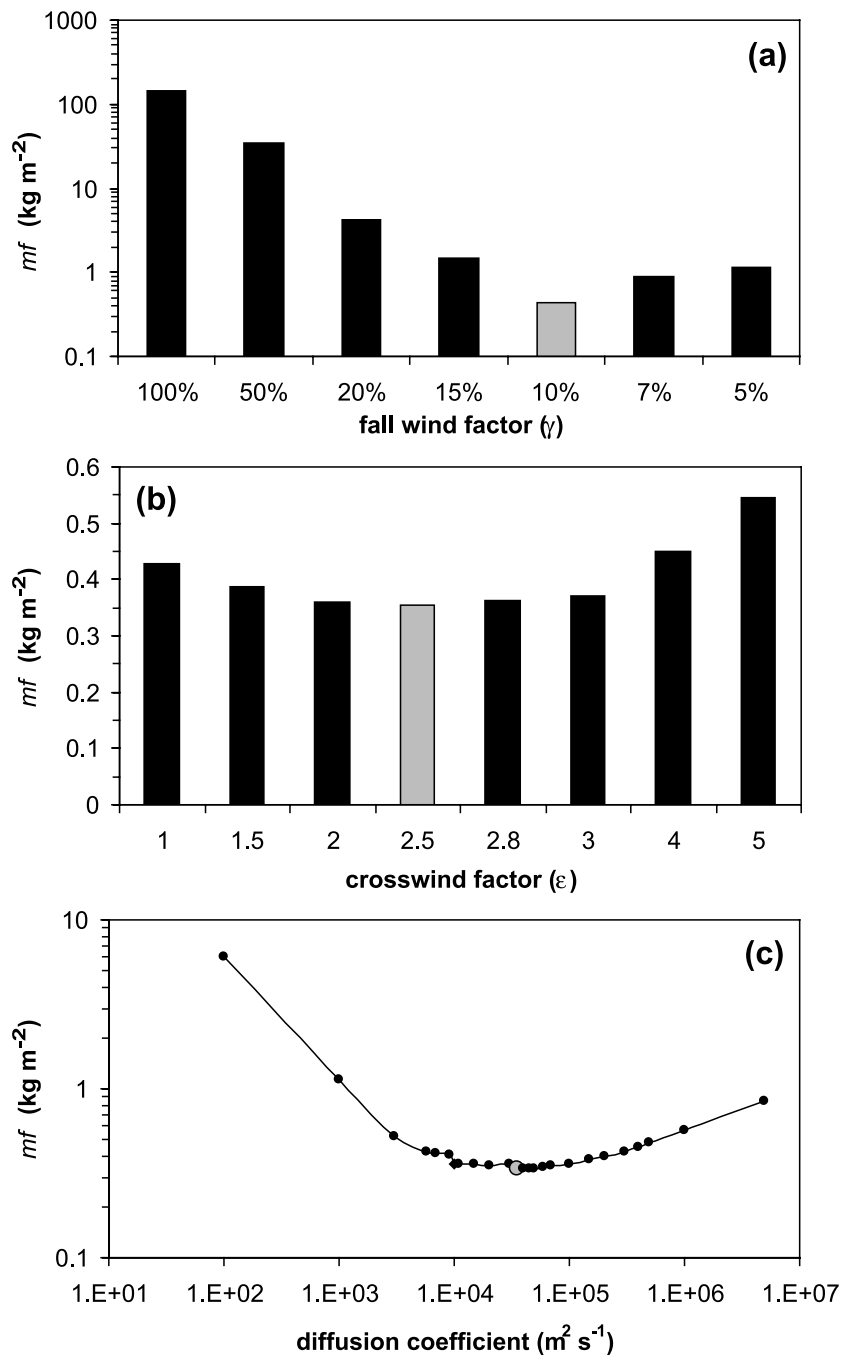

Figure 14. Misfit function $\left(m f, \mathrm{~kg} \mathrm{~m}^{-2}\right)$ for medial to distal points (i.e., distance from vent $4-180 \mathrm{~km}$ ) from the Ruapehu tephra deposit calculated for (a) fall wind factor $(\gamma$; semilog plot), (b) crosswind factor $(\varepsilon)$, and (c) diffusion coefficient (log-log plot). The gray symbols in all plots indicate the minimum value of $m f$ corresponding to the best fit value. See Table 1 for parameters used in the simulations (runs 7-9).

be expected, with the largest values necessary to describe the most vigorous weak plumes such as Ruapehu.

[45] To match field data, we find that we need to introduce an empirical fall wind factor with a value of about 0.1 , because the model predicts much greater deposition at a given downwind distance than is observed (Figure 12a). First of all, wind velocities underneath the spreading plume are likely to be lower than those described by radiosonde data from the Paraparaumu Aerodrome used in the simulations, particularly close to the ground. Second, tornado-like structures have been observed in the wake region of bent-over plumes due to the combination of vorticity stretching and conservation of the angular momentum [Fric and Roshko, 1994; Thorarinsson and Vonnegut, 1964]. These tornado-like structures are likely to result in quasi-vertical particle sedimentation. Finally, particle depo- sition could also be prevented by the strong entrainment velocity field underneath the bent-over plume. In fact, a significant effect of strong entrainment field into a twophase flow is to oppose the removal and sedimentation of particles [Phillips et al., 2000]. Although we account for the effect of the greater entrainment constant for weak plumes as compared to strong plumes in the value of the diffusion coefficient, we do not account for the effect of entrainment velocity field on particle sedimentation. As a conclusion, a thorough study of the wind and entrainment fields underneath a bent-over plume is crucial to our understanding of particle sedimentation from weak plumes.

[46] The Ruapehu tephra deposit is very narrow and characterized by a sinuosity that tends to isolate mass accumulation maxima, as seen at about $150 \mathrm{~km}$ from the vent in the total isomass map and at 100 and $150 \mathrm{~km}$ in the isomass map for particles with diameter less than $125 \mu \mathrm{m}$ (Figures 4 and 8 ). The sinuosity could be produced by horseshoe vortices forming around the base of the plume. In fact, bent-over plumes are likely to produce regularly spaced vortices in the boundary layer region near the ground [Fric and Roshko, 1994; Sparks et al., 1997]. However, isomass maps for individual sizes suggest that such a sinuosity is a size-selective process, as it is not shown by particles with diameter greater than $125 \mu \mathrm{m}$ (Figures 6 and 7). This suggests that sinuosity is likely to be a result of particle aggregation and/or deposition from instability structures that could isolate several accumulation maxima.

[47] Aggregates were not preserved in the final deposit at the time of tephra sampling, but millimetric clusters were observed during tephra fall (Houghton et al., submitted manuscript, 2005). Instability structures are also common during tephra fall [Bonadonna et al., 2002b; Carey, 1997; Hoyal et al., 1999] and were observed during the Ruapehu eruption (Houghton et al., submitted manuscript, 2005). Both particle aggregation and instability structures enhance

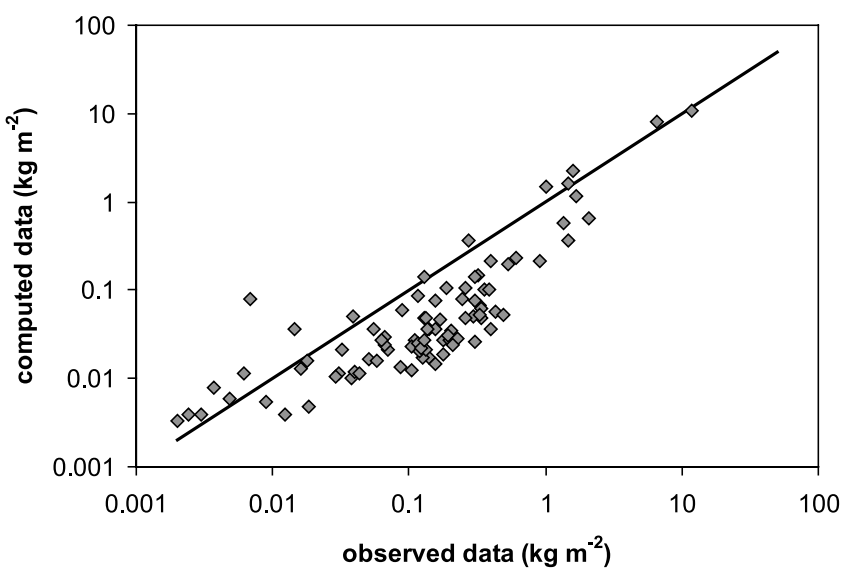

Figure 15. Logarithmic plot showing the comparison between observed data used in the sensitivity tests (Figure 14) and data computed with the best fit values for diffusion coefficient, fall wind factor, and crosswind factor (i.e., $k=3.5 \times 10^{4} \mathrm{~m}^{2} \mathrm{~s}^{-1}, \gamma=0.1$, and $\varepsilon=2.5$; see Table 1). The equiline is also shown for a better comparison. Also see Table 1 for all parameters used in the simulation (run 10). 
(a) computed accumulation at the current base $\left(\mathrm{m}_{\mathrm{aT}}\right)$

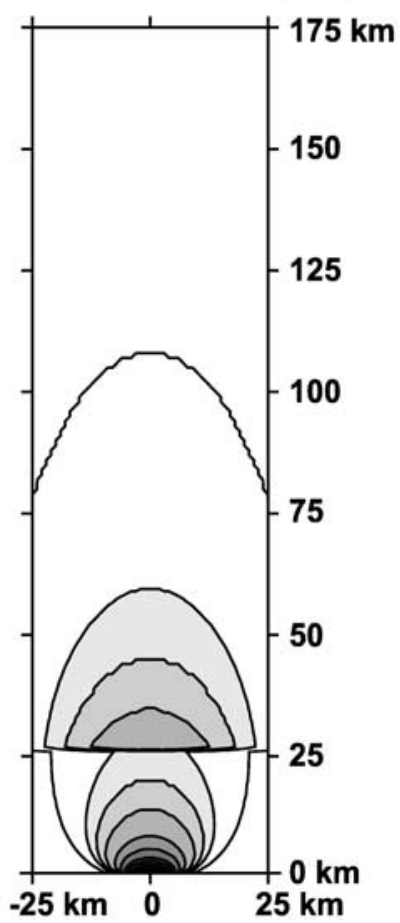

(b) computed sedimentation at the ground $\left(\mathrm{S}_{\mathrm{T}}\right)$

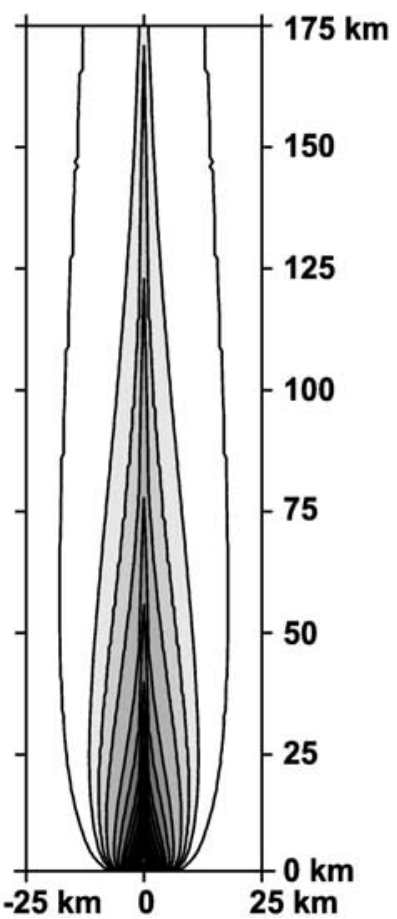

Figure 16. Isomass maps compiled for (a) computed tephra accumulation at the base of the spreading current (run 11 in Table 1) and (b) computed sedimentation at the ground (run 12 in Table 1). Computed data were contoured as in Figure 13. All contours are in $\mathrm{kg} \mathrm{m}^{-2}$, and distances are in $\mathrm{km}$ from the vent. Note the double maximum (i.e., accumulation between 0.05 and $0.2 \mathrm{~kg} \mathrm{~m}^{-2}$ ) around $27 \mathrm{~km}$ from vent in Figure $16 \mathrm{a}$ due to the change in plume-spreading regime from bent over to horizontal. This double maximum is not shown in Figure $16 \mathrm{~b}$ because of the smoothing effect of the wind. Also compare Figure $16 \mathrm{~b}$ with the field data map in Figures 4 and $13 \mathrm{c}$.

sedimentation of fine ash, by causing the particles to settle at velocities higher than their terminal velocities [Carey and Sigurdsson, 1982; Carey, 1997]. Convective instabilities and aggregation could also be enhanced by tornado-like structures, which is another characteristic structure typically forming in the wake of the spreading bent-over plume [Fric and Roshko, 1994; Thorarinsson and Vonnegut, 1964]. Finally, the interaction of weak plumes with topography has been shown to generate Lee waves which are likely to enhance various phase changes involving water in the plume and therefore could also enhance aggregation processes [Rose et al., 1988]. As a conclusion, the sinuosity is likely to be produced by the combination between bent-over plume structures (i.e., horseshoe vortices, tornado-like structure and Lee waves) and particle sedimentation processes (i.e., convective instabilities and aggregation).

[48] The width of isomass contours in Figure 4 can be described by Fickian diffusion using two contrasting diffusion coefficients within two different spreading regimes: $3 \times 10^{2} \mathrm{~m}^{2} \mathrm{~s}^{-1}$ within $23 \mathrm{~km}$ and $3 \times 10^{3} \mathrm{~m}^{2} \mathrm{~s}^{-1}$ between 46 and $225 \mathrm{~km}$ from vent (Figure 10). The different spreading regimes are associated with different sedimentation regimes. During the initial stage of plume rise (up to $23 \mathrm{~km}$ downwind from vent), Ruapehu sedimentation was mostly concentrated along the dispersal axis with a steep profile in the crosswind mass/area data, whereas during horizontal spreading (beyond $46 \mathrm{~km}$ from vent) the crosswind mass/area profile was flatter (Figures 4 and 10). These two sedimentation regimes are separated by a transitional phase between 23 and $46 \mathrm{~km}$ from, indicating that the transition between the two spreading regimes predicted by our model ( $27 \mathrm{~km}$ from vent) is probably too sharp. This is supported by observations of lapilli sedimentation which is mostly confined to within $30 \mathrm{~km}$ of the vent (wt $\%>0.1 \mathrm{~kg} \mathrm{~m}^{-2}$; Figure $5 \mathrm{c}$ ), but actually ends about $45 \mathrm{~km}$ from vent ( $\sim 0.02 \mathrm{wt} \%$; Figure $5 \mathrm{c})$. The beginning of horizontal spreading around $30 \mathrm{~km}$ from vent is also supported by satellite observations (A. J. Prata, personal communication, 2004).

[49] The Ruapehu plume produced a deposit characterized by no significant tephra accumulation upwind, rapid decrease of mass accumulation in proximal areas (within $10 \mathrm{~km}$ downwind from vent) and more gradual thinning in distal areas. The rapid decrease in mass accumulation within $10 \mathrm{~km}$ corresponds to a rapid decrease in lapilli deposition and rapid increase in coarse ash (Figure 5c). Between $10 \mathrm{~km}$ and $30 \mathrm{~km}$ sedimentation was mainly characterized by lapilli and coarse ash. Beyond $30 \mathrm{~km}$, when the plume started spreading horizontally, sedimentation was characterized by coarse and fine ash, with mostly fine ash falling beyond $100 \mathrm{~km}$ from the vent. However, plume sedimentation is 
dominated by coarse ash throughout, which is always present in proportions greater than $50 \mathrm{wt} \%$, with the exception of samples within $0.4 \mathrm{~km}$ from vent (Figure 5c). This type of deposition contrasts with typical depositional patterns from strong plumes. As an example, Bursik et al. [1992b] have shown that large clasts (typically $>2 \mathrm{~cm}$ diameter) are lost from the margins of the gas thrust and convective region of strong plumes and deposited around the vent, whereas smaller lapilli and coarse ash are predominantly carried to the top of the column and deposited from the base of the spreading umbrella cloud.

[50] Resulting sedimentation flux for well-mixed weak plumes is proportional to $\sim \exp \left(-x^{1 / 6}\right)$ and $\sim \exp \left(-x^{1 / 2}\right)$ during plume rise, and to $\sim \exp \left(-x^{3 / 2}\right)$ when the plume starts spreading horizontally (equation (12)). The sedimentation flux for strong-plume umbrella clouds developing in still air is proportional to $\sim \exp \left(-x^{2}\right)$, and that for umbrella clouds distorted by wind is proportional to $\sim \exp \left(-x^{3 / 2}\right)$ [Bonadonna and Phillips, 2003]. In conclusion, sedimentation from horizontally spreading currents from well-mixed weak plumes and from strong plumes occurs at the same rate.

[51] Samples collected along the dispersal axis all show a unimodal distribution with most of the fine ash deposited in distal areas (less than $10 \% \mathrm{wt}$ within $75 \mathrm{~km}$ from the vent; Figure $5 \mathrm{c}$ ), in contrast to the typical bimodal distribution that results from aggregation processes [Brazier et al., 1983]. However, the Ruapehu total grain size contains only $3 \mathrm{wt} \%$ fine ash and most of the blocks and lapilli fell within $30 \mathrm{~km}$ (Figure 5c). Therefore the tephra left in the plume during the horizontal spreading was mostly coarse ash and aggregation processes and convective instabilities could not result in striking bimodality. We conclude that sedimentation from the Ruapehu plume during the horizontal spreading (beyond $\sim 27 \mathrm{~km}$ from vent) was characterized by convective instabilities and aggregation processes that affected particles with diameter less than $125 \mu \mathrm{m}$ and resulted in at least two double maxima downwind at about $100 \mathrm{~km}$ and $150 \mathrm{~km}$ (Figure 8). These double maxima for particles with diameter less than $125 \mu \mathrm{m}$ resulted in a striking sinuosity in the total tephra deposit (Figure 4).

[52] Quantifying the effect of particle distribution within a volcanic plume on tephra sedimentation is likely to be a key issue in improving the quality of tephra dispersal modeling. The Gaussian structure of spreading plumes represents the basic assumption of so-called "integral models" derived from the theory of Morton et al. [1956] and was introduced to improve dispersal models still based on "top hat" profiles [e.g., Bursik et al., 1992b; Sparks et al., 1992]. However, simulations from recent $3 \mathrm{D}$ models for buoyant plumes in a vertically sheared cross flow based on the Navier-Stokes equations and solved using both direct numerical simulations (DNS) and large-eddy simulations (LES) do not show any Gaussian cross section at any single time or even as a time mean property [e.g., Cunningham et al., 2005]. The resulting cross-flow structure is closer to a kidney shape as also supported by the extensively studied theory of nonbuoyant jets in a cross flow, which are typically characterized by a counterrotating vortex pair [Fric and Roshko, 1994]. In conclusion, new investigations of more complex models are needed to assess the applicability of simplified models that also allow particle sedimentation to be described.

\section{Conclusions}

[53] The excellent data set available for the tephra deposit from the 17 June 1996 eruptive event of Ruapehu (New Zealand), allows some consideration on spreading and deposition from weak plumes to be made.

[54] 1. The Ruapehu eruption produced two weak plumes with a 2 hour separation, which were advected toward the NNE by a strong wind (average of $24 \mathrm{~m} \mathrm{~s}^{-1}$ during plume rise) with average differential downwind velocity of 24 and $19 \mathrm{~m} \mathrm{~s}^{-1}$ for the two plumes respectively. The corresponding lateral velocity was 4 and $6 \mathrm{~m} \mathrm{~s}^{-1}$ respectively, with the velocity of the second plume appearing larger due to the distal bifurcation that started when the plume lost its vigor (about 10 hours after the beginning of the eruption).

[55] 2. The Ruapehu deposit is characterized by no significant tephra upwind, rapid decrease of mass accumulation in proximal area and more gradual thinning in distal areas.

[56] 3. Different spreading regimes of the Ruapehu plume correspond to contrasting sedimentation regimes, with the sedimentation during the rising phase being concentrated around the dispersal axis with a very strong lateral variation and the sedimentation during horizontal spreading being characterized by a more gradual crosswind variation and a wider depositional area.

[57] 4. The lateral thinning variation shows a maximum at the dispersal axis, indicating that the subhorizontal spreading plume was well mixed at its centerline by vorticity and turbulence.

[58] 5. Blocks, lapilli and part of the coarse ash fraction were deposited from the rising stages of the weak plume (within $\sim 30 \mathrm{~km}$ from vent), whereas the horizontal spreading was characterized by coarse and fine ash.

[59] 6. Particles with diameter $>1 \mathrm{~mm}$ fall off steeply within the first $50 \mathrm{~km}$, whereas particles with diameter $<125 \mu \mathrm{m}$ show two maxima within $200 \mathrm{~km}$ from vent (at about 100 and $150 \mathrm{~km}$ from vent).

[60] 7. The double maxima of particles with diameter $<125 \mu \mathrm{m}$ result in a striking sinuosity of the total tephra deposit with a pronounced secondary maximum of mass accumulation at $150 \mathrm{~km}$ from vent. Such a sinuosity is shown to be size-selective and could be due to particle aggregation and convective instability structures enhanced by bent-over plume structures (i.e., horseshoe vortices, tornado-like structures and Lee waves).

[61] 8. Both plume spreading and deposit width can be described by the Fickian law of diffusion but with very different diffusion coefficients: $9 \times 10^{4} \mathrm{~m}^{2} \mathrm{~s}^{-1}$ for deposit width between 13 and $200 \mathrm{~km}$ from vent; $3 \times 10^{4} \mathrm{~m}^{2} \mathrm{~s}^{-1}$ for the plume spreading between 43 and $800 \mathrm{~km}$ from vent; $3 \times 10^{3} \mathrm{~m}^{2} \mathrm{~s}^{-1}$ for the proximal plume vertical thickness between 0.3 and $8.6 \mathrm{~km}$ from vent and for individual distal isolines between 46 and $225 \mathrm{~km}$ from vent $\left(\right.$ mass $/$ area $\left.=1-0.1 \mathrm{~kg} \mathrm{~m}^{-2}\right) ; 3 \times 10^{2} \mathrm{~m}^{2} \mathrm{~s}^{-1}$ for individual proximal isolines between 0.3 and $23 \mathrm{~km}$ from vent $\left(\right.$ mass $/$ area $\left.=3000-5 \mathrm{~kg} \mathrm{~m}^{-2}\right)$. 
[62] 9. Crosswind spreading during bifurcation (between 800 and $936 \mathrm{~km}$ from vent) cannot be described by Fickian diffusion and is proportional to $x^{3}$.

[63] On the basis of the interaction with atmospheric wind, eruptive plumes can be distinguished into (1) strong plumes, (2) well-mixed weak plumes, and (3) pair-vortex weak plumes. A new sedimentation model for well-mixed weak plumes is presented that shows good agreement with the Ruapehu field data and plume observations. On the basis of

[64] 1. Sedimentation from well-mixed weak plumes can be modeled as deposition from turbulent currents, where a gradient of increasing particle concentration is established due to the opposing effects of particle settling and turbulent diffusion, and the current spreading is controlled by the Fickian diffusion and an increasing volumetric flux downwind.

[65] 2. Sedimentation flux of well-mixed weak plumes is proportional to $\sim \exp \left(-x^{1 / 6}\right)$ and $\sim \exp \left(-x^{1 / 2}\right)$ during the first two phases of plume rise, and to $\sim \exp \left(-x^{3 / 2}\right)$ when the plume starts spreading horizontally.

[66] 3. One-dimensional and two-dimensional investigations show that the change in plume rise regime from bent over to horizontal results in a secondary maximum of mass accumulation at the current base. This maximum is not shown in the ground sedimentation due to the sorting effects of the wind advection.

[67] 4. Numerical investigations of the Ruapehu plume show a transition between rising plume $\left(z_{c}=\beta_{2} x^{1 / 2}\right)$ and horizontal spreading $\left(z_{c}=H_{b}\right)$ at $27 \mathrm{~km}$ from vent.

[68] 5. Observation and theoretical data show that proximal crosswind spreading and plume vertical thicknesses are roughly equivalent ( $<10 \mathrm{~km}$ from vent).

[69] 6. The sedimentation model presented shows good agreement with field data only when allowance is made for air entrainment (described by the empirical constants $\gamma$ and $\varepsilon)$. In fact, a simple Fickian model coupled with a Gaussian particle distribution underestimates the crosswind sedimentation and overestimates the downwind sedimentation. In addition, the sinuosity of the deposit cannot be reproduced because the model does not describe more complex phenomena, such as aggregation processes, convective instabilities, vorticity and plume pulsations.

[70] 7. One-dimensional and two-dimensional investigations of tephra sedimentation suggest that sedimentation from the Ruapehu weak-plume must have been subvertical.

[71] 8. Two-dimensional simulations show a best fit value of diffusion coefficient $\left(3.5 \times 10^{4} \mathrm{~m}^{2} \mathrm{~s}^{-1}\right)$ in agreement with the best fit values for plume lateral spreading observed between 43 and $800 \mathrm{~km}$ from vent $\left(3 \times 10^{4} \mathrm{~m}^{2} \mathrm{~s}^{-1}\right)$. These values are significantly larger than values typically observed for strong and "low-energy" weak plumes, suggesting that the Fickian law of diffusion can be used to predict the lateral expansion of "vigorous" weak plumes but a wide range of diffusion coefficients is to be expected.

\section{Notation}

$b$ characteristic length scale of plume radius or width [L], equation (12).

$B_{1}, B_{2}, B_{3}$ weak-plume sedimentation parameters $\left[\mathrm{L}^{-1 / 2}\right]$, equation (9).
$F$ buoyancy flux $\left[\mathrm{L}^{4} \mathrm{~T}^{-3}\right]$.

$H_{b}$ height of plume neutral buoyancy level [L].

$H_{c b}$ height of the current base of the plume (Figure 1) [L], equivalent to $z^{\prime}$ in equation (15).

$H_{t}$ total plume height [L].

$k$ diffusion coefficient $\left[\mathrm{L}^{2} \mathrm{~T}^{-1}\right]$, equation (5).

$M$ total mass of a given grain size fraction at the base of the spreading current [M], equation (4).

$M_{o}$ initial mass of a given grain size fraction [M], equation (4).

$m_{a}$ mass of a given grain size fraction per unit area at the base of the spreading current $\left[\mathrm{M} \mathrm{L}^{-2}\right]$, equation (11).

$m_{a T}$ total mass per unit area at the base of the spreading current $\left[\mathrm{M} \mathrm{L}^{-2}\right]$, equation (14).

$m_{c b}$ mass of a given grain size fraction per unit distance at the base of the spreading current $\left[\mathrm{M} \mathrm{L}^{-1}\right]$, equation (10).

$m f$ misfit function [Bonadonna et al., 2002a] $\left[\mathrm{M} \mathrm{L}^{-2}\right]$.

$p$ coefficient of the equation describing the particle fall trajectory $\lambda$, i.e., $p=\frac{v_{a v}^{\prime}}{u_{a v}^{\prime}}$, equation (16).

$Q$ volumetric flux $\left[\mathrm{L}^{3} \mathrm{~T}^{-1}\right]$, equations (7) and (8).

$Q_{\max }$ maximum volumetric flux, i.e., volumetric flux within the horizontal spreading region $\left[\mathrm{L}^{3} \mathrm{~T}^{-1}\right]$, equation $(8 \mathrm{c})$.

$S$ mass of a given grain size fraction deposited per unit area $\left[\mathrm{M} \mathrm{L}^{-2}\right]$, equation (18a).

$S_{T}$ total mass of sediment deposited per unit area $\left[\mathrm{M} \mathrm{L}^{-2}\right]$, equation (18b).

$u_{a}$ wind speed [ $\left.\mathrm{L} \mathrm{T}^{-1}\right]$.

$u_{a v}$ wind speed averaged along the plume rise, i.e., rise wind $\left[\mathrm{L} \mathrm{T}^{-1}\right]$.

$u_{a v}^{\prime}$ wind speed averaged along the trajectory of particle fall, i.e., fall wind $\left[\mathrm{L} \mathrm{T}^{-1}\right]$.

$v$ particle terminal velocity $\left[\mathrm{L} \mathrm{T}^{-1}\right]$.

$v_{a v}^{\prime} \quad$ particle terminal velocity averaged along the trajectory of particle fall $\left[\mathrm{L} \mathrm{T}^{-1}\right]$.

$w$ maximum crosswind width of the current spreading [L], equation (5).

$(x, y, z)$ coordinate system with $x$ along the dispersal axis and $y$ in the crosswind direction (Figure $1 b$ ).

$x_{a}$ downwind distance of mass accumulation at the base of the current and on ground in the case of vertical particle fall [L].

$x_{b}$ downwind distance of mass sedimentation on ground in the case of advected particle fall [L].

$x_{0}$ position of the turbulent current source, i.e., vent position in this weak-plume model [L].

$x_{1}, x_{2}$ downwind distances of the transition between first and second and second and third plume rise regimes [L], equation (2).

$x_{\mathrm{w}}$ shift downwind of a particle due to wind transport, i.e., $x_{b}-x_{a}$ [L], Figure 1 .

$y_{a}$ crosswind distance of mass accumulation at the base current and sedimentation on ground [L].

$z^{\prime} \quad$ height of the base of the spreading current, $H_{c b}$ in Figure $1 \mathrm{~b}[\mathrm{~L}]$, equation (15).

$z_{c}$ height of the centerline of the spreading current [L]. 
$z_{p}$ fall height of a given particle size varying between $H_{c b}$ and the ground along the trajectory $\lambda$, Figure $1 \mathrm{~b}$ and equation (16).

$\alpha$ weak-plume entrainment constant, which can be either $\alpha_{G}$ or $\alpha_{T}$ depending on the initial assumption.

$\alpha_{G}$ weak-plume entrainment constant for the Gaussian model, i.e., 0.35.

$\alpha_{T}$ weak-plume entrainment constant for the "top hat" model, i.e., 0.5.

$\beta_{1}$ plume rise constant of the weak-plume centerline (first bent-over region) $\left[\mathrm{L}^{1 / 3}\right]$, equation (1a).

$\beta_{2}$ plume rise constant of the weak-plume centerline (second bent-over region) $\left[\mathrm{L}^{1 / 2}\right]$, equation (1b).

$\beta_{1}^{\prime} \quad$ plume rise constant of the weak-plume current base (first bent-over region) $\left[\mathrm{L}^{1 / 3}\right]$, equation (15a).

$\beta_{2}^{\prime}$ plume rise constant of the weak-plume current base (second bent-over region) $\left[\mathrm{L}^{1 / 2}\right]$, equation (15b).

$\gamma$ fall wind factor.

$\Delta$ particle fall angle; see Figure $1 \mathrm{~b}$.

$\varepsilon$ crosswind factor, equation (25).

$\lambda$ trajectory of particles during fall; see Figure $1 \mathrm{~b}$.

$\Lambda$ weak-plume sedimentation parameter, equation (17a).

$\Phi$ granulometric unit: $\Phi=-\log _{2} \mathrm{~d}$, where $\mathrm{d}$ is the grain size in $\mathrm{mm}$.

$\omega_{1}$ parameter of volume flux for weak plumes $\left[\mathrm{L}^{2 / 3}\right]$; see equation (8).

$\omega_{2}$ parameter of volume flux for weak plumes [L]; see equation (8).

[72] Acknowledgments. Many thanks to Steve Sparks for a very constructive review of the original manuscript. The authors are also grateful to Fred Prata for providing radiosonde data and continuous support during the project. We also thank Bill Rose, an anonymous Associate Editor, and an anonymous reviewer for constructive comments and suggestions. This work was initiated at the University of Bristol (UK) and terminated at the University of Hawai'i at Manoa. C Bonadonna was supported by an EC Marie Curie Ph.D. Fellowship in Bristol and by the SOEST Young Investigator Program and NSF-EAR-0310096 at the University of Hawai'i. J. C. Phillips was supported by the University of Bristol.

\section{References}

Armienti, P., G. Macedonio, and M. T. Pareschi (1988), A numerical-model for simulation of tephra transport and deposition: Applications to May 18 1980, Mount St. Helens eruption, J. Geophys. Res., 93(B6), 6463-6476.

Bonadonna, C., and B. F. Houghton (2005), Total grainsize distribution and volume of tephra-fall deposits, Bull. Volcanol., 67, 441-456, doi:10.1007/s00445-004-0386-2.

Bonadonna, C., and J. C. Phillips (2003), Sedimentation from strong volcanic plumes, J. Geophys. Res., 108(B7), 2340, doi:10.1029/ 2002JB002034.

Bonadonna, C., G. G. J. Ernst, and R. S. J. Sparks (1998), Thickness variations and volume estimates of tephra fall deposits: The importance of particle Reynolds number, J. Volcanol. Geotherm. Res., 81(3-4), $173-187$.

Bonadonna, C., G. Macedonio, and R. S. J. Sparks (2002a), Numerical modelling of tephra fallout associated with dome collapses and Vulcanian explosions: Application to hazard assessment on Montserrat, in The Eruption of Soufrière Hills Volcano, Montserrat, From 1995 to 1999 , edited by T. H. Druitt and B. P. Kokelaar, Geol. Soc. Mem., 21, 517-537.

Bonadonna, C., et al. (2002b), Tephra fallout in the eruption of Soufrière Hills Volcano, Montserrat, in The Eruption of Soufrière Hills Volcano,
Montserrat, From 1995 to 1999, edited by T. H. Druitt and B. P. Kokelaar, Geol. Soc. Mem., 21, 483-516.

Bonadonna, C., C. B. Connor, B. F. Houghton, L. Connor, M. Byrne, A. Laing, and T. Hincks (2005), Probabilistic modeling of tephra dispersion: Hazard assessment of a multiphase eruption at Tarawera, New Zealand, J. Geophys. Res., 110, B03203, doi:10.1029/2003JB002896.

Brazier, S., R. S. J. Sparks, S. N. Carey, H. Sigurdsson, and J. A. Westgate (1983), Bimodal grain-size distribution and secondary thickening in air fall ash layers, Nature, 301, 115-119.

Briggs, G. A. (1969), Plume Rise, 80 pp., U.S. Atomic Energy Commission, Washington, D. C.

Briggs, G. A. (1975), Plume rise predictions, in Lectures on Air Pollution and Environmental Impact Analyses, pp. 59-111, Am. Meteorol. Soc., Boston, Mass.

Bursik, M. (1998), Tephra dispersal, in The Physics of Explosive Volcanic Eruptions, edited by J. S. Gilbert and R. S. J. Sparks, Geol. Soc. Spec. Publ., 145, 115-144.

Bursik, M. I., S. N. Carey, and R. S. J. Sparks (1992a), A gravity current model for the May 18, 1980 Mount St. Helens plume, Geophys. Res. Lett., 19(16), 1663-1666.

Bursik, M. I., R. S. J. Sparks, J. S. Gilbert, and S. N. Carey (1992b), Sedimentation of tephra by volcanic plumes: I. Theory and its comparison with a study of the Fogo A plinian deposit, Sao Miguel (Azores), Bull. Volcanol., 54, 329-344.

Carey, S. N. (1997), Influence of convective sedimentation on the formation of widespread tephra fall layers in the deep sea, Geology, 25(9), 839842 .

Carey, S. N., and H. Sigurdsson (1982), Influence of particle aggregation on deposition of distal tephra from the May 18, 1980, eruption of Mount St. Helens volcano, J. Geophys. Res., 87(B8), 7061-7072.

Carey, S. N., and R. S. J. Sparks (1986), Quantitative models of the fallout and dispersal of tephra from volcanic eruption columns, Bull. Volcanol., $48,109-125$.

Coelho, S. L. V., and J. C. R. Hunt (1989), The dynamics of the near-field of strong jets in crossflows, J. Fluid Mech., 200, 95-120.

Cunningham, P., S. L. Goodrick, M. Y. Hussaini, and R. R. Linn (2005), Coherent vortical structures in numerical simulations of buoyant plumes from wildland fires, Int. J. Wildland Fire, 14(1), 61-75.

Ernst, G. G. J., J. P. Davis, and R. S. J. Sparks (1994), Bifurcation of volcanic plumes in a crosswind, Bull. Volcanol., 56, 159-169.

Ernst, G. G. J., R. S. J. Sparks, S. N. Carey, and M. I. Bursik (1996), Sedimentation from turbulent jets and plumes, J. Geophys. Res., 101(B3), 5575-5589.

Fric, T. F., and A. Roshko (1994), Vortical structure in the wake of a transverse jet, J. Fluid Mech., 279, 1-47.

Glaze, L. S., and S. Self (1991), Ashfall dispersal for the 16 September 1986, eruption of Lascar, Chile, calculated by a turbulent-diffusion model, Geophys. Res. Lett., 18(7), 1237-1240.

Heffter, J. L. (1965), The variation of horizontal diffusion parameters with time for travel periods of one hour or longer, J. Appl. Meteorol., 4, 153156.

Hoyal, D., M. I. Bursik, and J. F. Atkinson (1999), The influence of diffusive convection on sedimentation from buoyant plumes, Mar. Geol., $159(1-4), 205-220$.

Hurst, A. W., and R. Turner (1999), Performance of the program ASHFALL for forecasting ashfall during the 1995 and 1996 eruptions of Ruapehu volcano, N. Z. J. Geol. Geophys., 42(4), 615-622.

Koyaguchi, T., and M. Ohno (2001), Reconstruction of eruption column dynamics on the basis of grain size of tephra fall deposits: 1. Methods, J. Geophys. Res., 106(B4), 6499-6512.

Macedonio, G., M. T. Pareschi, and R. Santacroce (1988), A numerical simulation of the Plinian fall phase of $79 \mathrm{AD}$ eruption of Vesuvius, J. Geophys. Res., 93(B12), 14,817-14,827.

Morton, B., G. L. Taylor, and J. S. Turner (1956), Turbulent gravitational convection from maintained and instantaneous source, Proc. R. Soc. London, 234, 1-23.

Pasquill, F. (1974), Atmospheric Diffusion, John Wiley, Hoboken, N. J.

Phillips, J. C., P. C. H. Miller, and N. H. Thomas (2000), Air flow and droplet motions produced by the interaction of flat-fan sprays and cross flows, At. Sprays, 10(1), 83-103.

Prata, A. J., and I. F. Grant (2001), Retrieval of microphysical and morphological properties of volcanic ash plumes from satellite data: Application to Mt Ruapehu, New Zealand, Q. J. R. Meteorol. Soc., 127(576), $2153-2179$.

Rose, W. I., G. Heiken, K. Wohletz, D. Eppler, S. Barr, T. Miller, R. L. Chuan, and R. B. Symonds (1988), Direct rate measurements of eruption plumes at Augustine volcano: A problem of scaling and uncontrolled variables, J. Geophys. Res., 93(B5), 4485-4499.

Sparks, R. S. J., M. I. Bursik, G. J. Ablay, R. M. E. Thomas, and S. N. Carey (1992), Sedimentation of tephra by volcanic plumes. 2. Controls 
on thickness and grain-size variations of tephra fall deposits, Bull. Volcanol., 54(8), 685-695.

Sparks, R. S. J., M. I. Bursik, S. N. Carey, J. S. Gilbert, L. S. Glaze, H. Sigurdsson, and A. W. Woods (1997), Volcanic Plumes, 574 pp., John Wiley, Hoboken, N. J.

Suzuki, T. (1983), A theoretical model for dispersion of tephra, in Arc Volcanism, Physics and Tectonics, edited by D. Shimozuru and I. Yokoyama, pp. 95-113, Terra Sci., Tokyo.

Thorarinsson, S., and B. Vonnegut (1964), Whirlwind produced by the eruption of Surtsey Volcano, Bull. Am. Meteorol. Soc., 45, 440444
Turner, J. S. (1973), Buoyancy Effects in Fluids, 368 pp., Cambridge Univ. Press, New York.

C. Bonadonna, Department of Geology, University of South Florida, Tampa, FL 33620, USA. (costanza@cas.usf.edu)

B. F. Houghton, Department of Geology and Geophysics, University of Hawai'i at Manoa, Honolulu, HI 96822, USA. (bhought@soest.hawaii.edu)

J. C. Phillips, Centre for Environmental and Geophysical Flows, University of Bristol, Bristol, BS8 1RJ, UK. (j.c.phillips@bristol.ac.uk) 